\title{
A Systematic Review of PET Textural Analysis and Radiomics in Cancer
}

\author{
Manuel Piñeiro-Fiel 1,2®0 , Alexis Moscoso 1,2, Virginia Pubul ${ }^{2}$, Álvaro Ruibal 1,2,3, Jesús Silva-Rodríguez ${ }^{2, *}$ \\ and Pablo Aguiar 1,2
}

1 Molecular Imaging and Medical Physics Group, Radiology Department, Faculty of Medicine, Universidade de Santiago de Compostela, 15706 Santiago de Compostela, Spain; manuelpifiel@gmail.com (M.P.-F.); alexis.moscoso@rai.usc.es (A.M.); alvaro.ruibal.morell@sergas.es (Á.R.); pablo.aguiar.fernandez@gmail.com (P.A.)

2 Molecular Imaging Research Group, Nuclear Medicine Department, University Hospital and Health Research Institute of Santiago de Compostela (IDIS), 15706 Santiago de Compostela, Spain; virginia.pubul.nunez@sergas.es

3 Fundación Tejerina, José Abascal, 40, 28003 Madrid, Spain

* Correspondence: jesus@qubiotech.com

check for updates

Citation: Piñeiro-Fiel, M.; Moscoso, A.; Pubul, V.; Ruibal, Á.;

Silva-Rodríguez, J.; Aguiar, P. A Systematic Review of PET Textural Analysis and Radiomics in Cancer. Diagnostics 2021, 11, 380. https://doi. org/10.3390/diagnostics11020380

Academic Editor: Damiano Caruso

Received: 13 January 2021

Accepted: 19 February 2021

Published: 23 February 2021

Publisher's Note: MDPI stays neutral with regard to jurisdictional claims in published maps and institutional affiliations.

Copyright: (c) 2021 by the authors. Licensee MDPI, Basel, Switzerland. This article is an open access article distributed under the terms and conditions of the Creative Commons Attribution (CC BY) license (https:// creativecommons.org/licenses/by/ $4.0 /)$.

\begin{abstract}
Background: Although many works have supported the utility of PET radiomics, several authors have raised concerns over the robustness and replicability of the results. This study aimed to perform a systematic review on the topic of PET radiomics and the used methodologies. Methods: PubMed was searched up to 15 October 2020. Original research articles based on human data specifying at least one tumor type and PET image were included, excluding those that apply only firstorder statistics and those including fewer than 20 patients. Each publication, cancer type, objective and several methodological parameters (number of patients and features, validation approach, among other things) were extracted. Results: A total of 290 studies were included. Lung (28\%) and head and neck $(24 \%)$ were the most studied cancers. The most common objective was prognosis/treatment response (46\%), followed by diagnosis/staging (21\%), tumor characterization (18\%) and technical evaluations $(15 \%)$. The average number of patients included was 114 (median $=71$; range 20-1419), and the average number of high-order features calculated per study was 31 (median $=26$, range 1-286). Conclusions: PET radiomics is a promising field, but the number of patients in most publications is insufficient, and very few papers perform in-depth validations. The role of standardization initiatives will be crucial in the upcoming years.
\end{abstract}

Keywords: PET; radiomics; heterogeneity; textural analysis; cancer

\section{Introduction}

Decades of research on cancer biology have revealed that tumors are heterogeneous entities at all scales (macroscopic, physiological, microscopic and genetic) [1-4], with different regions showing distinct morphological and phenotypic profiles [5-7]. Nowadays, it is widely accepted that tumor heterogeneity has profound implications in tumor development, therapeutic outcomes and survival [8-11], making it essential to develop methods for studying tumor heterogeneity in vivo [12].

In this context, non-invasive imaging techniques, such as magnetic resonance (MR), computed tomography (CT) and positron emission tomography (PET) become relevant due to their ability to provide information on the whole tumor in one acquisition [13]. Nowadays, imaging is central to cancer management, having applications in screening, diagnosis, staging, prognosis and treatment response, among other things [14-18]. Mainly, PET has emerged as the predominant imaging modality, overperforming conventional imaging techniques for the evaluation of blood [19], head and neck [20] or lung cancer [21]; and it has been increasingly proposed as an ideal tool for characterizing the biology 
of tumors at the macroscopic scale [13,22-25]. Over the last years, there has been an increasing interest in extracting quantitative information from PET images using image analysis [26,27]. Thus, semi-quantitative parameters such as the standard uptake value (SUV), the metabolic tumor volume (MTV) or the total lesion glycolysis (TLG) [28] obtained from ${ }^{18}$ F-fluorodeoxyglucose PET (FDG-PET) images, have been demonstrated to provide relatively objective information useful for the diagnosis, earlier evaluation and monitoring of treatment response $[24,25,28]$. These parameters are now fully incorporated into clinical guidelines and commonly measured at most hospitals in developed countries [29].

Several research studies have pointed out that high-order textural features derived from PET images can provide information about tumor heterogeneity, expanding the information available from clinical reports, laboratory tests and genomic or proteomic assays $[26,27,30]$. This has led to the incorporation of PET imaging to radiomics, a new medical imaging field exploiting image features to develop novel diagnostic, predictive and prognostic multiparametric models to support personalized clinical decisions and improve individualized treatment selection [27,31,32] (Figure 1). Textural analysis has long been applied in CT [33] and MRI [34], but it had not been introduced in PET until the last decade. Since then, increasing numbers of studies have suggested that PET textural features would be correlated with tumor biology and heterogeneity [35-42], providing valuable information for tailoring individual treatments $[13,18,23,43-46]$.

a)

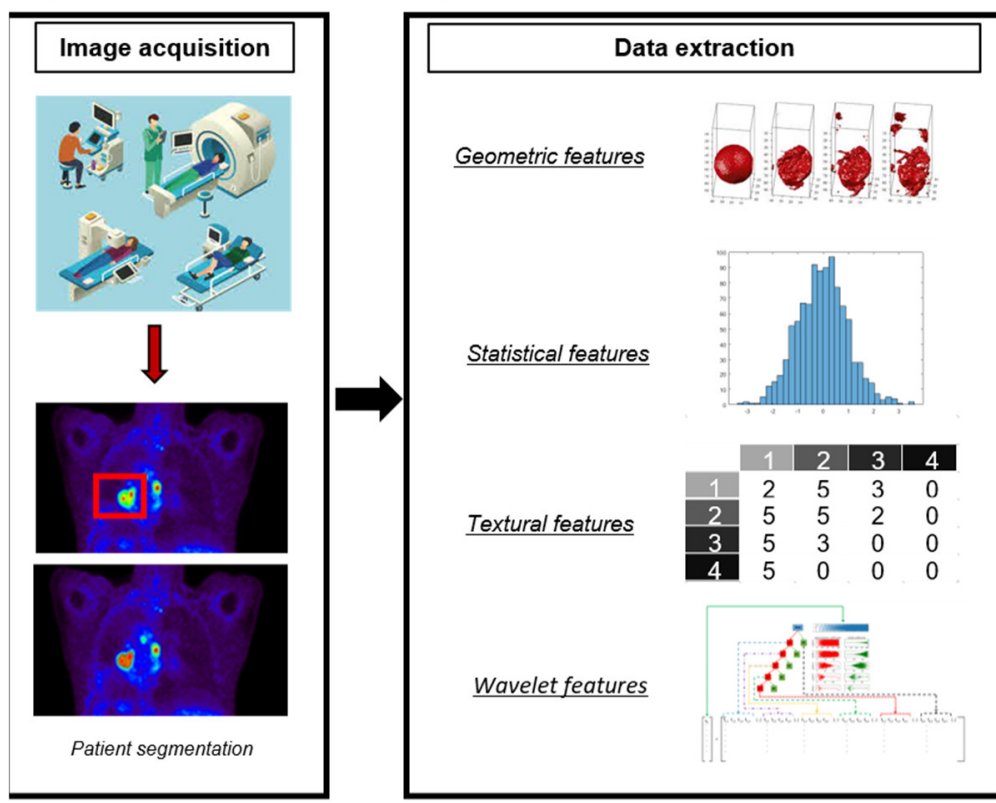

c)

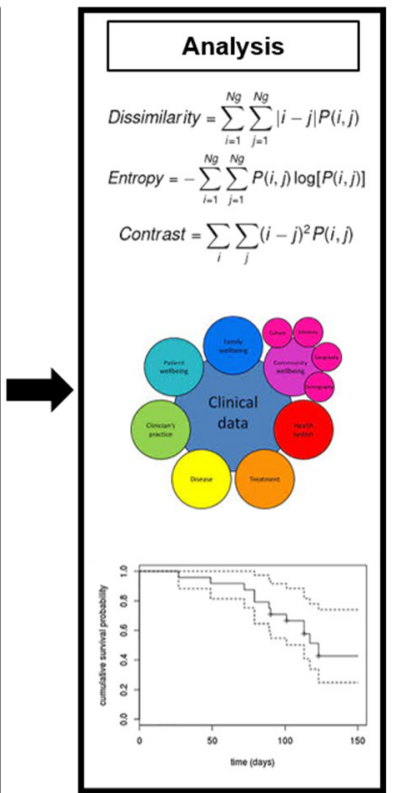

Figure 1. Example of image processing for radiomics. (a) Image acquisition and tumor segmentation. (b) Extraction of different shape, intensity, and textural features from the segmented tumor. (c) Development of prediction models using imaging features.

Despite the promising early reports, numerous studies have highlighted the challenges to be addressed before the use of PET radiomics becomes reliable and interpretable [46]. In addition to issues common to PET imaging itself, such as noise or partial volume effects [47-49], radiomics must deal with standardization issues related to the differences in acquisition and reconstruction parameters, post-processing techniques, tumor segmentation methods or even texture calculations [46,50-53]. The complex formulation of radiomics makes it challenging to explain pervasive findings such as the correlations displayed between different texture indices [54-60], as well as strong correlations between textural indices and tumor volume [61-63], which compromise the added value of these parameters in comparison with SUV or MTV. Furthermore, the variability in definitions and nomenclature of heterogeneity metrics themselves complicate any evaluation and comparison of 
published results [64]. Finally, there is no consensus about how many patients are needed, which textures must be extracted, or what methodologies should be applied for proper validation $[24,46,52]$.

Due to the prominent role of quantitative image analysis in the diagnosis, tumor characterization and prognosis of cancer patients, the development of reliable and wellvalidated image analysis methods is of paramount importance. Particularly, parallel with the popularization of PET radiomics, several authors have highlighted the methodological and statistical issues in their works. In the present work, we provide a systematic review on the topic of PET radiomics, with a special emphasis on the applied methodologies and validation strategies.

\section{Experimental Section}

We computed this systematic review from 1 September to 15 October 2020. This review's reporting complies with the PRISMA-P Preferred Reporting Items for Systematic Reviews and Meta-Analyses statement [65].

\subsection{Search Strategy/Eligibility Criteria}

We performed a comprehensive literature search to identify eligible articles in the PubMed database searching for the presence of the combination of terms "(PET) AND ((radiomics) OR (texture) OR (textural))". Results were admitted from 1 January 1990, up to and including 15 October 2020. The included articles satisfied all the eligibility criteria given in the subsequent paragraphs.

The inclusion criteria were (1) articles that included (in all fields) at least two of the search words specified in the search string; (2) studies based on human data specifying at least one tumor type; and (3) PET image was included.

The exclusion criteria were as follows: (1) studies not within the field of interest, i.e., not related to medical imaging, or applying PET textural analysis to diseases other than cancer, (2) preclinical and or animal studies, (3) studies including only testing data (i.e., phantoms, simulated data), (4) studies including less than 20 patients (for studies including several types of cancer, the articles were included if they provided data from 20 or more patients of at least one type), (5) case reports, reviews, poster presentations, conference abstracts and expert opinion papers, (6) articles including only first-order PET features in their analysis (SUV, MTV, TLG, or histogram features) and (7) articles not written in English.

\subsection{Data Collection, Selection Process and Items}

After applying the inclusion and exclusion criteria, a review-specific electronic database (Microsoft Excel) was generated to handle document collection, data extraction forms and disseminate findings during all the study phases (abstract screening, eligibility and evaluation). As a final step, the full text of the included articles was evaluated.

From each article, the following information was extracted and annotated in the database:

1. Cancer of body organs or systems, such as blood, brain, breast, gynecological, head and neck, liver or lung. Articles including patients of several cancer types were included in each category separately.

2. Number of patients in a study (for studies evaluating several types of cancers separately, the number of patients for each was included and evaluated under the corresponding category).

3. Radiotracer in use.

4. Imaging modalities included in the radiomics analysis: PET, PET+CT, PET+MRI, PET+CT+MRI, other (note that not using PET for radiomics was an exclusion criterion).

5. Type and number of imaging features extracted: first-order features (intensity: SUV and histogram features, shape or volume) and high-order features (textures). For the high-order features, the radiomics matrices used for feature extraction were annotated (grey-level co-occurrence matrix (GLCM), grey-level size zone matrix (GLZSM), grey- 
level run length matrix (GLRLM) or other). We also annotated if works used wavelet processing for data augmentation.

6. Objective defining whether the article is focused on diagnosis/staging, prognosis/treatment response or tumor characterization. Publications aiming at the evaluation of technical factors were included in a separated category.

7. Level of statistical validation evaluated with an ad-hoc scale. We ranked it poor in case of the absence of statistical analysis, average if statistics and radiomics were available on a single cohort (i.e., ROC analysis, Cox regression), good when findings were corroborated on a separate subsample and very good if validation against an independent cohort was available (i.e., from a different center/scanner).

8. We annotated if the analyzed work found first-order or high-order features useful for the defined objective when available. This information is not present in every paper, as some of them only report the number of features in the final model without detailing the features included after processing. Furthermore, when methodologies such as deep learning are applied, this information is not be available.

\subsection{Data Analysis}

Full-text reviews were performed by two of the authors independently (M.P.F. and J.S.R.). Afterwards, discrepancies in their interpretation were identified and solved by consensus between all the authors. An initial assessment of the number of articles on each cancer group was made to select the most representative tumor types. We provide a separate section for those representing more than $5 \%$ of the gathered papers in the Results. The rest of the articles were included in a single group labelled as "Other".

\subsection{Quality Assessment}

The same two reviewers performed quality assessment of the included studies. The assessment was performed using the ROBVIS tool (https: / / www.riskofbias.info/, accessed on 10 February 2021). The studies were assessed for three items:

1. The number of patients, where studies with fewer than 50 patients were considered to have a high risk of bias; between 50 and 100 patients, some concerns; and more than 100 patients, low risk of bias. This rationale was adapted from the recommendations provided by Gillies et al. [31].

2. Risk of overfitting, where studies with fewer than three patients per evaluated features were considered to have a high risk of bias; between three and five, some concerns; and more than five patients per features, low risk of bias. This rationale was adapted from the recommendations provided by Papanikolaou et al. [66].

3. Level of statistical validation, where studies providing poor validation according to the scale above were considered to have a high risk of bias; average validation, some concerns; and good" or very good validation, low risk of bias.

Moreover, the overall score was given using the mode of the three punctuations. If the three scores were different, the overall score was "Some concerns".

\section{Results}

\subsection{Search Selection}

The search process (Figure 2) returned a total of 744 publications. Three duplicated records were identified and removed. Titles and abstracts of the remaining 741 records were screened. After screening, we excluded 386 records due to inclusion/exclusion criteria. Full texts of the remaining 355 records were inspected. Sixty-five articles were excluded due to inclusion/exclusion criteria or incomplete information after a detailed assessment. Finally, a total of 290 full-text articles were included in the review. A complete list of the evaluated publications along with the data extracted from each publication can be found in the Supplementary Material Table S1. Using this selection, we corroborated the increasing pace of publications in PET radiomics in the later years. According to our findings, the first papers on PET radiomics appeared in 2009-2012 (one publication per year), and the number 
of publications started to rise after 2013 (eight publications), with nine publications in 2014 (+13\% interannual increase), 19 in 2015 (+111\% interannual increase), 20 in $2016(+5 \%$ interannual increase), 44 in 2017 (+120\% interannual increase), 46 in 2018 (+5\% interannual increase), 66 in 2019 (+43\% interannual increase), and 74 publications in 2020 (up to October 15) (+12\% interannual increase) (Figure 3$)$.

\section{PRISMA 2009 Flow Diagram}
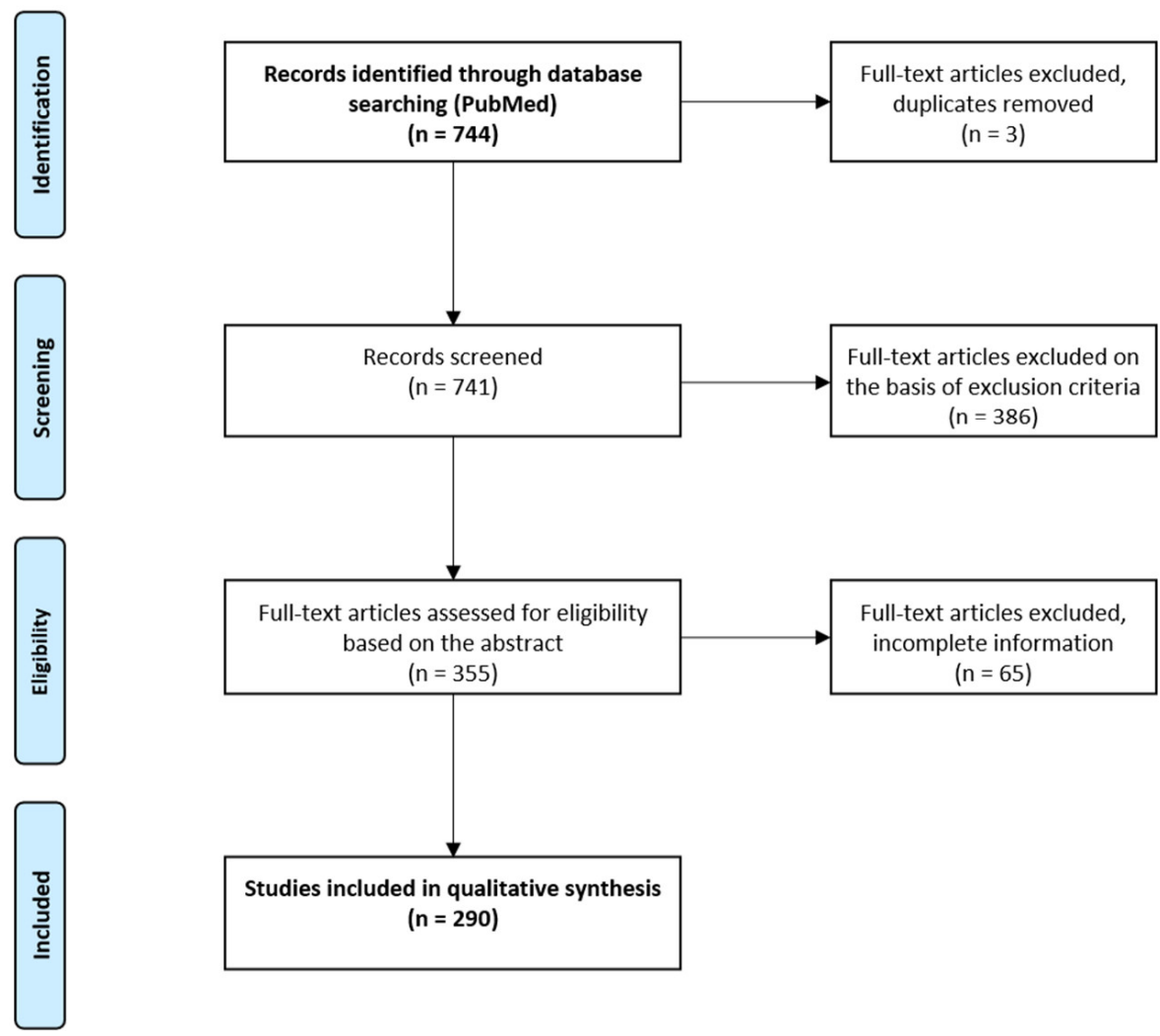

Figure 2. Preferred Reporting Items for Systematic Reviews and Meta-Analyses flow diagram.

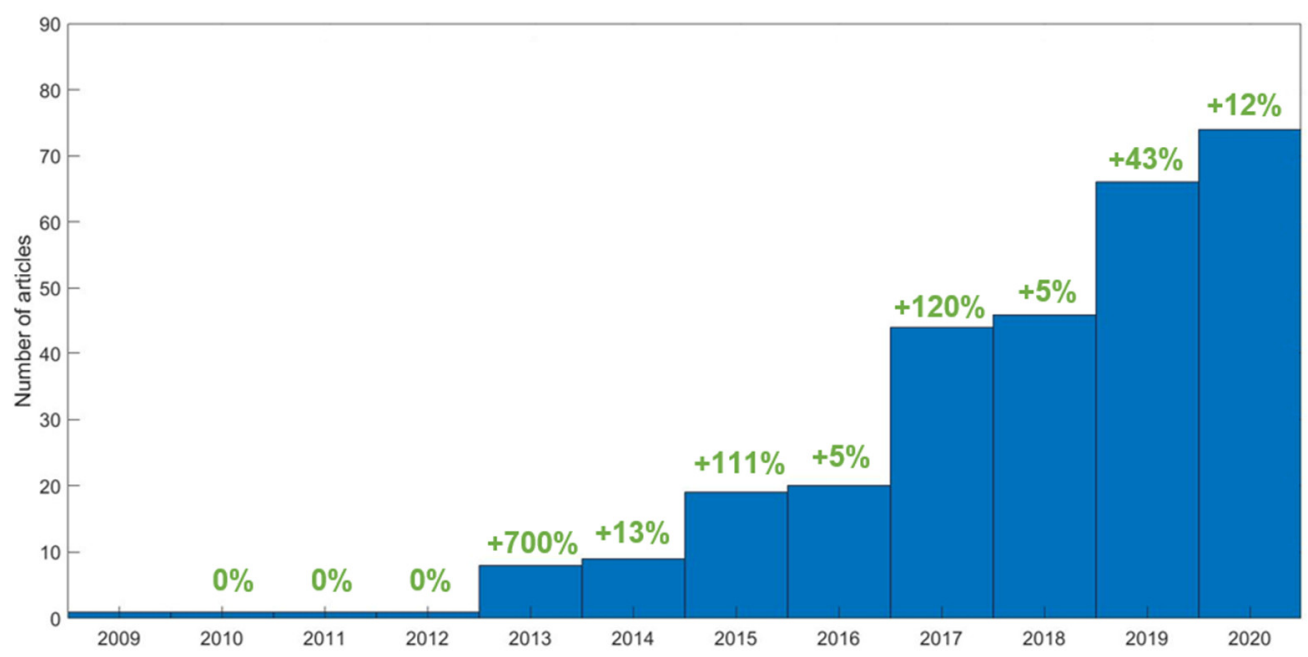

Figure 3. The number of publications per year. In green, the interannual increase. 


\subsection{Data Analysis}

\subsubsection{Database Characterization}

Figure 4 shows the distribution of the evaluated publications by cancer types. In the following sections, we provide detailed data for cancer types representing more than $5 \%$ of the publications, namely: lung $(71,24 \%)$, head and neck $(44,15 \%)$, breast $(20,7 \%)$, gynecological $(19,7 \%)$, blood $(18,6 \%)$ and brain $(17,6 \%)$ cancer. The rest of the publications were synthesized in a category labelled as "Other". Articles focusing on technical factors were evaluated independently. A meta-analysis of the whole database can be summarized as follows:

1. The average number of patients included was 114 (median $=71$; range, 20-1419). A considerable number of studies $(187,64 \%)$ included fewer than 100 patients.

2. The average number of high-order features calculated per study was 31 (median $=26$, range, 1-286). Most papers combined high-order with first-order features such as SUV $(97 \%)$, volume or shape features $(91 \%)$ and intensity histogram features such as kurtosis or skewness $(76 \%)$.

3. The most common matrices employed for texture calculation were the GLCM (included in 95\% of the studies), GLZSM (63\%) and the GLRLM (58\%).

4. Most of the studies included features only from PET (76\%), followed by those studies combining PET and CT features (18\%) or PET with MRI (16, 5\%).

5. Regarding the PET radiotracer, almost all the studies were performed using FDG data $(91 \%)$ or combining FDG with another tracer $(2 \%)$. Only a small number of studies $(6 \%)$ were focused exclusively on other tracers.

6. The most common study objective was prognosis/treatment response (46\%), followed by diagnosis/staging (21\%) and tumor characterization (18\%). A total of $15 \%$ of the studies were dedicated to the analysis of technical factors. Figure 5 shows the distribution of objectives for the six most common cancer types in the meta-analysis.

7. Most of the studies presented average $(60 \%)$ or good $(32 \%)$ levels of validation, and only a small number of studies performed proper validation using independent cohorts $(8 \%)$.

a)
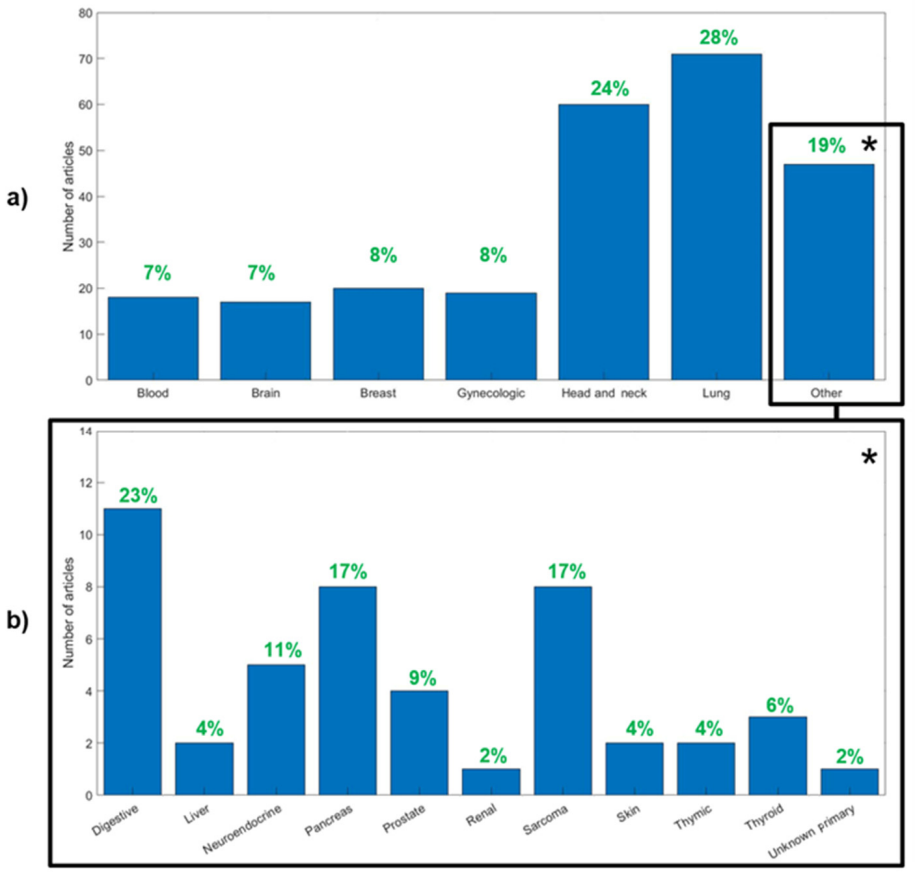

Figure 4. The number of articles associated with each cancer type group. (a) Number of patients per number of groups studied in the present review. (b) Distribution of cancer types in the "Other" group. In green, the percentage of publications corresponding to that group. ${ }^{*}$ Percentages in panel (b) represent the percentage in the "Other" group. 
a)

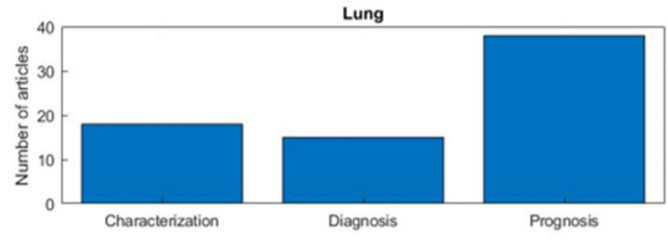

c)

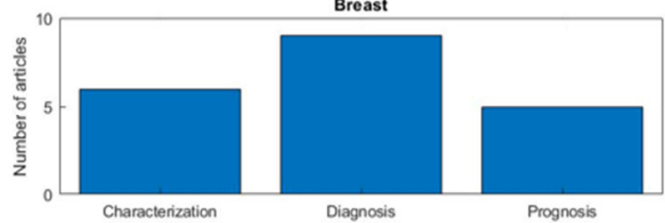

Blood

e)

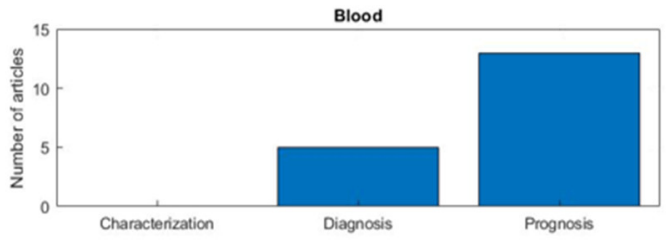

b)

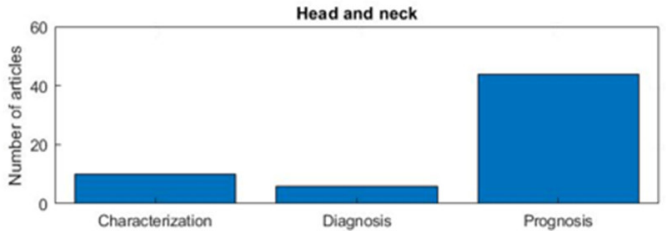

d)

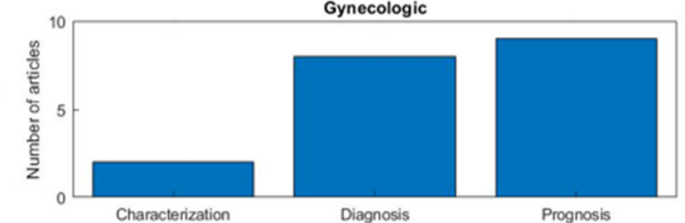

Brain

f)

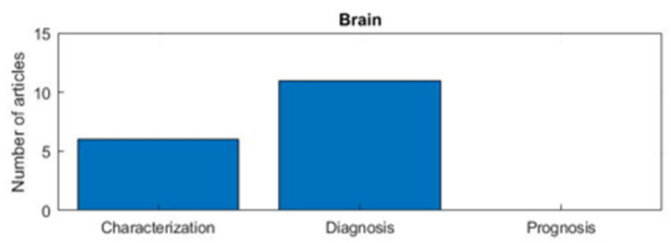

Figure 5. Studies targeting each of the defined objectives segmented by cancer type. (a) Lung, (b) head and neck, (c) breast, (d) gynecologic, (e) blood, (f) brain cancer.

\subsubsection{Quality Assessment}

Out of the 290 publications evaluated, 109 were judged to have a low risk of bias, 131 were judged as having some concerns, and the remaining 50 were at a high risk of bias. A synthesis of the results for the three evaluated items is shown in Figure 6. The complete evaluation can be found in the Supplementary Material Table S2.

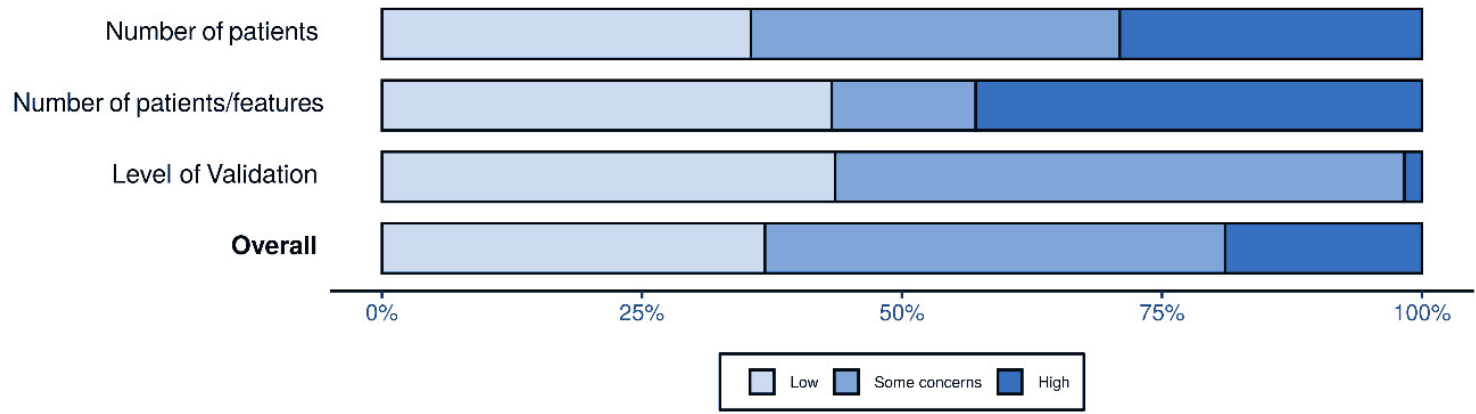

Figure 6. Per item and overall risk of bias.

\subsection{Main Types of Cancer}

\subsubsection{Lung Cancer}

We collected 71 articles evaluating lung cancer [37,57,58,67-129], of which 57 (80\%) were focused on non-small-cell lung cancer (NSCLC). The average number of patients per study was 157 (median $=102$, range, 22-1419) and the average number of studied textural features was 33 (median $=27$, range, 1-286). GLCM was the most employed feature calculation matrix (92\%) followed by GLRLM and GLSZM (50-55\%). Eleven studies (15\%) used wavelet filtering in the preprocessing for augmenting input feature numbers. A total of $97 \%$ of the publications reported that the inclusion of high-order features improved the performance of previous models. Although most of the studies used PET data only (62\%), a relatively large subset (38\%) used a multimodal approach combining PET and CT features. The radiotracer was FDG for all the studies. Regarding validation, $49 \%$ of the studies were classified as providing average statistical evidence, while 35\% were classified as good and $11 \%$ as very good. 
The objective was diagnosis/staging in $20 \%$ of the publications, tumor characterization-in $25 \%$ of the publications, and prognosis/treatment response-in 54\% of the publications. Especially relevantly, Kirienko et al. [79] compared the ability of PET and CT radiomics for differentiating primary and metastatic lung lesions in a pool of 482 patients, finding that only PET features were predictive. Other studies that focused on diagnosis demonstrated the ability of PET radiomics to distinguish between malign and benign FDG-avid lesions $[67,71,74]$ or between tuberculosis and lung cancer $[75,80]$. Regarding characterization, in a study including 867 patients, Han et al. [129] showed that PET radiomics in combination with deep learning was able to differentiate histological subtypes of cancer, particularly, adenocarcinoma and squamous cell carcinoma. Other studies showed the ability of PET radiomics to predict EGFR mutation status [68,95,111,115] or PD-L1 expression [127]. As for prognosis, Arshad et al. [125] developed a prognostic model for the risk stratification of NSCLC patients, which was validated in several independent cohorts, including different scanner models and reconstruction protocols. The authors used first-order metrics, several texture matrices and wavelet filtering to get up to 665 features per tumor and concluded that a feature set independent of known prognostic factors could predict survival after radiotherapy/chemoradiotherapy. In contrast, in a recent study that included two independent cohorts, Konert et al. [126] concluded that PET radiomic features did not have a complementary value in predicting overall survival compared to conventional metrics.

\subsubsection{Head and Neck Cancer}

We collected information from 60 articles that satisfy our selection criteria and evaluated head and neck cancer [28,82,130-187]. The average number of patients was 126 (median $=72$, range, 20-707), and the average number of calculated textural features was 33 (median $=24$, range, 1-98). The GLCM was the most common matrix for feature calculation (93\%), followed by the GLSZM (62\%) and the GLRLM (55\%). Most studies combined textural features with first-order statistics (93\% of the studies included SUV, $85 \%$ - shape/volume, $82 \%$ - histogram features), and eight studies (13\%) used wavelet filtering for multiplying feature numbers. Forty-four studies included only PET data, fourteen studies (23\%) combined PET and CT data, and two studies (3\%) combined PET and MR data. FDG was the most common radiotracer (93\%), but some studies also included data from ${ }^{18}$ F-fluoromisonidazole (FMISO) (3\%) and ${ }^{18}$ F-fluorothymidine (FLT) (3\%). Most studies provided average validation $60 \%)$, followed by good $(26 \%)$ and very good validation (13\%). Regarding the objectives, $10 \%$ of the studies evaluated diagnosis/staging, $17 \%$ of the studies focused on tumor characterization and $73 \%$ of the studies evaluated prognosis/treatment response.

Among the most relevant works, Du et al. [132] evaluated the ability of radiomics to differentiate between recurrence and inflammation in nasopharyngeal carcinoma, obtaining an AUC of 0.89 . The method was validated in an independent subsample of the cohort. Choi et al. [150] evaluated the association between the tumor-stroma ratio and heterogeneity features. They found that coarseness (a feature from the neighborhood gray tone difference matrix (NGTDM) matrix) correctly evaluated this tumor characteristic $(A U C=0.741)$. Finally, regarding prognosis, Vallières et al. [182] used sophisticated machine learning strategies for developing a model predicting treatment outcome from FDG-PET and CT images of 300 patients. The model was developed using data from two different centers and validated independently on two additional cohorts. The developed model could predict locoregional recurrences and distant metastases with AUCs of 0.69 and 0.86 , respectively.

Similarly, Peng et al. [187] developed a model for selecting those patients that would benefit from induction chemotherapy. Sörensen et al. [145] investigated whether textural features on FMISO PET before chemoradiotherapy could identify patients with better overall survival, concluding that higher homogeneity of tumor hypoxia could correlate with a better outcome and open the door to novel applications of radiomics on novel 
tracers. Nevertheless, this study was performed in a limited cohort of 29 patients, and further evaluations including more patients are needed.

\subsubsection{Breast Cancer}

We evaluated 20 publications on breast cancer [59,188-206], all of them using FDG as the radiotracer. The average number of patients was 118 (median $=81$, range, 34-435). The average number of calculated textural features was 18 (median $=6$, range, 2-73), extracted mainly from the GLCM $(19 / 20,95 \%)$, the GLSZM (9/20, 45\%) and the GLRLM $(7 / 20,35 \%)$. All the evaluated papers included SUV, volume/shape, and histogram features. A total of $75 \%$ of the studies included PET data alone, while $20 \%$ combined PET and MR radiomics and one study $(5 \%)$ combined PET and CT. Fifteen studies (75\%) fell in the category of average validation. In comparison, five studies $(25 \%)$ were considered to provide good validation and $20 \%$ of the evaluated works focused on diagnosis/staging, $35 \%$ - on tumor characterization and $45 \%$ - on prognosis.

In one of the most relevant works assessing diagnosis, Ou et al. [194] evaluated the ability of PET and CT radiomics to differentiate breast carcinoma from breast lymphoma using a machine-learning approach. They validated their findings in a separate subsample of the cohort, obtaining an AUC of 0.81 for PET radiomics, which outperformed CT radiomics. Nevertheless, in a similar work, the same authors showed that this result might represent minimal improvement to the classification performance obtained by SUV alone [192]. In Moscoso et al. [203], the authors showed that PET textural features are correlated with immunohistochemical factors and the immunohistochemical subtype of breast cancer using images acquired using a dedicated breast PET scanner. Finally, Lee et al. [188] developed a statistical model combining clinicopathological factors and texture parameters from PET and CT images to predict individual responses to neoadjuvant chemotherapy.

\subsubsection{Gynecological Cancer}

We collected 19 publications focusing on gynecological cancers [82,104,207-223], particularly on cervical $(74 \%)$, endometrial $(16 \%)$, epithelial $(5 \%)$ and vulvar cancer $(5 \%)$. The average number of patients was 93 (median $=84$, range, 20-190). The average number of calculated textural features was 33 (median $=31$, range, 2-73). The most used heterogeneity matrices were the GLCM $(17 / 19,89 \%)$, followed by the GLRLM $(15 / 19,79 \%)$ and the GLZSM $(14 / 19,74 \%)$. All the publications used FDG as the radiotracer. Regarding modalities, 16 studies (84\%) used PET data only, and three studies (16\%) combined PET with MRI. All the evaluated papers combined textural features with SUV metrics, while 18 studies (95\%) included volume/shape measurements, and 14 studies (68\%) included first-order metrics derived from the intensity histogram. A total of $79 \%$ of the studies found that radiomic features were useful for the pursued objective, in most cases $(60 \%)$ accompanied by first-order metrics. Three studies (16\%) reported that only first-order metrics were predictive. As for the level of statistical validation, nine studies fell into the average validation category ( $47 \%)$, eight-into the good category, and two (11\%)—into the very good category. A total of $42 \%$ of the publications focused on diagnosis/staging, $11 \%$ - on tumor characterization, and $47 \%$ - on prognosis/treatment response.

Li et al. [211] evaluated the ability of PET radiomics to predict pelvic lymphatic metastases in patients with early-stage cervical squamous cell carcinoma. While the authors reported that some GLCM features might have value in predicting the vascular endothelial growth factors (VEGF), they found that the best staging was obtained when using TLG combined with histogram metrics. In a similar work, Shen et al. [212] concluded that homogeneity from the GLCM combined with TLG was the best combination of predictors, partially supporting these results. In a study involving 84 patients, Novikov [221] evaluated whether PET radiomic features of epithelial tumors would be able to predict the differentiation grade, reporting an accuracy between $91 \%$ and $100 \%$. Finally, regarding prognosis, Lucia et al. [223] presented one of a very few papers aiming at validating a previously developed radiomics model [222], providing compelling evidence of the ability 
of PET $+\mathrm{MR}$ radiomics to predict disease-free survival and locoregional control in locally advanced cervical cancer.

\subsubsection{Blood Cancer}

We collected 18 papers about radiomics in blood cancers [82,224-240], most of them focusing on non-Hodgkin lymphoma (11/18) and Hodgkin lymphoma (4/18). The average number of patients included was 77 (median $=51$, range, 24-251) and the average number of evaluated textures was 28 (median $=22$, range, 3-78), extracted mainly from the GLCM $(100 \%)$, the GLZSM $(56 \%)$ and the GLRLM $(50 \%)$. All the reviewed studies combined high-order features with some first-order parameters, such as volume or shape features $(100 \%)$, SUV (94\%) and histogram-derived parameters (50\%). All the publications used FDG. Regarding modalities, $72 \%$ of the studies explored PET radiomics, while the remaining $28 \%$ combined PET and CT textures. For the level of validation, 12 publications qualified as average (67\%), five-as good ( $28 \%$ ) and one-as very good (3\%). Of the studies, $55 \%$ reported that combining first-order parameters and high-order textures provided the best performance for the pursued objective, while $22 \%$ reported that the best models used only first-order parameters and $33 \%$ obtained the best results when using only high-order features. Regarding objectives, $34 \%$ of the papers focused on diagnosis/staging and $66 \%$ - on prognosis/treatment response.

Among the most relevant publications, Mayerhoefer et al. [226] investigated FDG-PET radiomics as an alternative to biopsy to assess bone marrow involvement in mantle cell lymphoma. They found that the developed radiomic signature combining PET textures with laboratory data had an AUC of 0.81 predicting bone marrow involvement with reasonable accuracy. Milgrom et al. [233] assessed whether radiomic features extracted from baseline PET scans predicted relapsed or refractory disease status in a cohort of 251 patients with stage I-II Hodgkin lymphoma and found that a model incorporating SUV, MTV and three high-dimensional features was able to predict primary refractory disease with a model AUC of 0.95 . The validation was carried out on a subset of the cohort not included in the training process. In contrast, Jamet et al. [231] developed a model for predicting transplant eligibility in newly diagnosed multiple myeloma using 139 patients from two independent cohorts. They concluded that a combination of SUV and clinical parameters is the best and most robust predictor after validation on an independent sample.

\subsubsection{Brain Cancer}

We collected 17 publications [225,241-256] focusing on the evaluation of brain tumors, most of them gliomas $(71 \%$ ). The average number of patients was 71 (median $=70$, range, 20-127) and the average number of evaluated textures was 40 (median $=33$, range, 2-75), extracted mainly from the GLCM $(94 \%)$, the GLZSM (65\%), and the GLRLM $(65 \%)$. All the studies combined textural features with SUV, volume or shape and histogram metrics. The most widely reported modality was PET (used in $76 \%$ of the studies), while $18 \%$ of the studies combined PET with MR and one study (6\%) included PET, MR and CT features. Aside from FDG, which was included in 39\% of the studies, six publications (33\%) included data using ${ }^{18} \mathrm{~F}$-2-fluorotyrosine (FET), three (18\%) - using ${ }^{18} \mathrm{~F}$-methionine (MET), one $\left(6 \%\right.$ - - using ${ }^{18}$ F-fluorodopa (FDOPA) and one study-using FMISO radiotracers. Regarding the level of validation, $71 \%$ of the studies provided good validation, $24 \%-$ average" validation and 6\%-very good validation. Regarding the objectives, $65 \%$ of the papers focused on diagnosis, targeting issues such as differentiating recurrence from radiation injury [244-246,248], while $35 \%$ of the studies evaluated tumor characterization.

Kong et al. [255] studied the correlation between radiomic features and proliferative activity in primary gliomas as measured by Ki-67 in 123 patients. The authors conclude that the developed radiomic signature could stratify patients into two distinct prognostic groups, with results comparable to those obtained with Ki-67. Li et al. [256] developed an FDG-PET radiomic model for predicting the isocitrate dehydrogenase (IDH) genotype and prognosis and obtained AUCs $>0.9$ for both the training and validation patient datasets. 
Finally, Qian et al. [253] developed a model for predicting the MGMT methylation status in glioblastoma patients using FDOPA images and obtained accuracy of around $80 \%$. The validation was carried out in an independent subsample of their dataset.

\subsubsection{Other Cancers}

We collected 47 publications on "Other" cancer types. This category included studies on gastrointestinal (11) [257-267], pancreatic (8) [268-275], sarcoma (8) [276-283], neuroendocrine (5) [284-288], prostate (4) [289-292], thyroid (3) [293-295], thymic (2) [296,297], skin (2) [298,299], liver (2) [300,301], and renal carcinomas (1) [302]. The average number of patients was 84 (median $=70$, range, 26-214) and the average number of textural features extracted was 29 (median $=17$, range, 1-236). In a similar manner to previous cases, GLCM $(44 / 47,94 \%)$ was the most common feature matrix, followed by GLSZM $(29 / 47,62 \%)$ and the GLRLM $(26 / 47,55 \%)$. Regarding modality, $42 / 47$ studies $(89 \%)$ used only PET data, while $2 / 47$ studies (4\%) combined PET and CT and $3 / 47$ studies $(6 \%)$ combined PET and MR data. The most common radiotracer was FDG $(38 / 47,81 \%)$, but the presence of edotreotide (DOTATOC)/DOTA-octreotate (DOTATATE) radiotracers was relevant in the papers evaluating neuroendocrine tumors $(4 / 5,80 \%)$. Prostate-specific membrane antigen (PSMA) radiotracers $\left({ }^{68} \mathrm{Ga}\right.$ or $\left.{ }^{18} \mathrm{~F}\right)$ were used for all papers focused on prostate cancer $(4 / 4$, $100 \%$ ). A total of $19 \%$ of the studies were focused on diagnosis/staging, $23 \%$ - on tumor characterization, and $57 \%$ - on prognosis/treatment response. Regarding the validation process, $36 / 47$ studies $(77 \%)$ presented average validation, while ten fell into the good validation category. Forty-four out of forty-seven papers $(94 \%)$ concluded that radiomic features provided predictive value for the pursued objectives, in most cases $(33 / 44,75 \%)$ in combination with first-order features.

\subsubsection{Technical Factors}

Finally, we found 44 papers evaluating technical factors [53,60-62,64,154,303-339], without pursuing a clinical objective. Of these, $30 \%$ evaluated the impact of different tumor segmentation methods. Among these, Hatt et al. [317] assessed the robustness of PET textural features among the segmentation methods with and without partial volume correction and provided a selection of features robust to these parameters. A total of $22 \%$ of the studies evaluated the impact of different acquisition and patient management protocols with a particular interest in the effects of respiratory motion. In this regard, Grootjans et al. [325] investigated the impact of respiratory motion and noise on textural features, concluding that respiratory motion significantly affected PET textures' quantification. Only $14 \%$ of the papers evaluated the impact of different reconstruction methods and parameters, and $9 \%$ of the studies assessed the correlation between textural features and conventional parameters such as SUV and MTV. Hatt et al. [62] found a significant correlation between heterogeneity features and MTV and observed that the textures' complementary information increased progressively with volume. Finally, $11 \%$ of the studies proposed and validated harmonization strategies and $14 \%$ of them evaluated other factors' influence.

\section{Discussion}

\subsection{Summary of the Main Findings}

The present work presents a comprehensive overview of the available literature in PET radiomics and textural analysis. We extracted detailed information from 290 articles after data curation according to the PRISMA-P methodology. We observed that the interest in PET radiomics increased exponentially in the last decade, and we expect that the current tendency will continue in the upcoming years.

Lung, head and neck, breast and gynecological cancers emerged as the most studied cancer types. It is well-known that radiomics is a demanding technique in terms of data, and thus we assume that this is a consequence of the prevalence of these types of cancer [340]. The average number of patients per study was 114 , and we observed that $65 \%$ of the evaluated publications included data from less than 100 patients (29\%, less than 50 patients). 
Previous works evaluating radiomic methodologies suggested a proportion of five patients per evaluated feature to avoid model overfitting [52,66] or a minimum of 100 patients [31]. Based on this and considering that the average number of high-order features was 31 (median $=26$, range, 1-286), we would recommend including larger numbers of patients in further works. In addition to this, a limited number of publications $(8 \%)$ provided a validation of the proposed models using independent databases or a validation in an independent subsample of the initial dataset $(28 \%)$. We assume that this fact is related to the small amount of data available. Publications with higher numbers of patients used resources such as The Cancer Imaging Archive (TCIA) [341]. We expect that the continuous growth of public imaging databases will improve these numbers in the future and provide a common playground where algorithms could be compared and validated. The rise of collaborative models such as federated learning [342,343] where different centers share models validated across centers while keeping their own data anonymous will also generate more robust algorithms in the near future.

Furthermore, we observed that very few papers aimed at externally validating previously developed models $[128,223]$. We believe that this should be a common practice in the field. Nevertheless, we observed that most of the publications did not provide easy access to the developed models. As for data sharing, accessibility of software is a substantial concern, reducing the applicability and potential impact of published studies and models [344]. The collaboration between centers and researchers should be improved for further model validation, which is needed to generalize PET radiomics. In this regards, van Griethuysen et al. recently released PyRadiomics, an open modular platform to provide the community with standard tools for promoting further independent development and evaluation [345].

Regarding the objectives of the evaluated publications, the evaluation of prognosis or treatment response was the most common (46\%), followed by diagnosis and staging (21\%), tumor characterization (articles aimed at predicting the biological characteristics of tumors traditionally obtained by other means (i.e., histology, genetics)) $(18 \%)$ and the evaluation of technical factors $(15 \%)$. This result is not surprising, as textures are intended to measure heterogeneity, well-known to be related to aggressiveness and poor outcomes [177-179]. We believe that more papers focused on tumor characterization and technical factors would be useful in this regard. On the one hand, although heterogeneity itself was proposed as a biomarker in the past $[346,347]$ it has been reported that heterogeneity is related to biological characteristics such as tumor microenvironment [348,349], genetic expression [350] and, macroscopically, tumor grades or cancer subtypes [351]; thus, linking radiomic features with particular biological characteristics could provide additional evidence for the field. On the other hand, further work is still needed to evaluate the impact of image acquisition, reconstruction, post-processing and feature calculation [352]. In an exemplary work, Bodowicz et al. investigated an association of PET radiomics with local tumor control after radiochemotherapy in head and neck cancer, developing radiomic implementations with two different software packages. Of the 649 features calculated, only $12 \%$ were reproducible between the two software implementations, and, although both models were similarly predictive, they included different sets of features, pointing to the need of further harmonization on feature calculation. Harmonization initiatives, such as the Image Biomarker Standardization Initiative [64], would be extremely helpful for this process, as reliable and reproducible measurements are of paramount importance for biomarkers to progress on their validation.

Most of the evaluated studies (78\%) concluded that the inclusion of textural features improved the results of models developed with clinical or first-order imaging metrics, which is a powerful conclusion. Nevertheless, it must be interpreted with caution since, as mentioned above, most of the evaluated studies included an insufficient number of patients or were not extensively validated. Many studies reported models including both first and high-order features, which were compared usually with counterparts including a reduced number of features, so an improvement of the result can be caused by overfitting $[353,354]$. 
Several papers from our group [63] and others $[60,126,317]$ have suggested a strong correlation between the most used textural features and conventional parameters such as MTV and SUV, which must be untangled.

In summary, PET radiomics is an up-and-coming field, and PET radiomics might have a role in clinical practice in the future. In this regard, the results of the most relevant papers are very appealing. Nevertheless, we have identified several methodological concerns related to the validation of the purposed algorithms, the number of patients included, the lack of data and software accessibility and a need for further methodological standardization. We have also observed that the community is already developing solutions to overcome these limitations.

\subsection{Limitations}

Our review presents several limitations. We selected studies with at least 20 patients for statistical reasons, which could cause the risk that tumors with low prevalence (or novel radiotracers) were systematically excluded from our analysis. Furthermore, we decided to divide the analyzed articles into six main groups, with one other group collecting all the cancer types representing less than $5 \%$ of the publications. This categorization might hide different approaches for different cancer types in this last group or among subtypes in the other groups. In addition to this, several papers investigated the application of radiomics to sites different from the primary tumor, such as those applying textural analysis to lymph nodes. These different approaches are not considered in the present review. Several publications did not fit our objective's classification as they evaluated more than one topic. In such cases, classifications were decided on consensus. We assume that this might systematically exclude secondary topics common to a high number of publications. Furthermore, we decided to report the total number of high-order features calculated by the authors instead of those found to be predictive/useful. This decision was made to better reflect the high heterogeneity in methodology across studies. Moreover, information about the number of useful features or how many of them were used was not available in many studies. Finally, although we obtained some information on the publication results, a more detailed analysis, potentially focusing independently on each type of cancer, is needed to assess, for example, if certain features are repeatedly found predictive for certain diseases.

\section{Conclusions}

The bibliography available on the topic of PET radiomics is exponentially increasing. Although most papers presented promising results, we found that the methodology was highly variable. Furthermore, we observed that the number of patients included in most publications was insufficient and that very few papers performed in-depth validations. Based on the obtained data, we can conclude that PET radiomics is a promising field in its early days of development, and we expect that the interest in PET radiomics will continue growing in the following years.

Supplementary Materials: The following are available online at https://www.mdpi.com/2075 $-4418 / 11 / 2 / 380 /$ s1, Table S1: List of articles reviewed, extracted information, Table S2: Risk of bias analysis.

Author Contributions: Conceptualization, P.A., J.S.-R. and V.P.; methodology, P.A. and J.S.-R.; data collection: M.P.-F.; formal analysis, M.P.-F., Á.R. and J.S.-R.; investigation, M.P.-F. and J.S.-R.; resources, P.A., V.P. and Á.R.; data curation, M.P.-F.; writing—original draft preparation, M.P.-F; writing—review and editing, J.S.-R., A.M. and P.A.; visualization, M.P.-F.; supervision, P.A.; project administration, P.A. All authors have read and agreed to the published version of the manuscript. Please turn to the CRediT taxonomy for the term explanation. Authorship must be limited to those who have contributed substantially to work reported.

Funding: This research was partially funded by DTS17/00138 (Instituto de Salud Carlos III) and ED431F 2017/04 project (GAIN-Xunta de Galicia). 
Conflicts of Interest: The authors declare no conflict of interest.

\section{References}

1. Gerlinger, M.; Rowan, A.J.; Horswell, S.; Larkin, J.; Endesfelder, D.; Gronroos, E.; Martinez, P.; Matthews, N.; Stewart, A.; Tarpey, P.; et al. Intratumor Heterogeneity and Branched Evolution Revealed by Multiregion Sequencing. N. Engl. J. Med. 2012, 366, 883-892. [CrossRef]

2. McGranahan, N.; Swanton, C. Biological and Therapeutic Impact of Intratumor Heterogeneity in Cancer Evolution. Cancer Cell 2015, 27, 15-26. [CrossRef]

3. Leskela, S.; Pérez-Mies, B.; Rosa-Rosa, J.M.; Cristobal, E.; Biscuola, M.; Palacios-Berraquero, M.L.; Ong, S.; Guia, X.M.-G.; Palacios, J. Molecular Basis of Tumor Heterogeneity in Endometrial Carcinosarcoma. Cancers 2019, 11, 964. [CrossRef]

4. Hass, R.; von der Ohe, J.; Ungefroren, H. Impact of the Tumor Microenvironment on Tumor Heterogeneity and Consequences for Cancer Cell Plasticity and Stemness. Cancers 2020, 12, 3716. [CrossRef] [PubMed]

5. Tellez-Gabriel, M.; Ory, B.; Lamoureux, F.; Heymann, M.-F.; Heymann, D. Tumor Heterogeneity: The Key Advantages of Single-Cell Analysis. Int. J. Mol. Sci 2016, 17, 2142. [CrossRef] [PubMed]

6. Michor, F.; Polyak, K. The Origins and Implications of Intratumor Heterogeneity. Cancer Prev Res. 2010, 3, 1361-1364. [CrossRef]

7. Visvader, J.E. Cells of Origin in Cancer. Nature 2011, 469, 314-322. [CrossRef]

8. Marusyk, A.; Polyak, K. Tumor Heterogeneity: Causes and Consequences. Biochim. Biophys. Acta 2010, 1805, 105-117. [CrossRef]

9. Roma-Rodrigues, C.; Mendes, R.; Baptista, P.V.; Fernandes, A.R. Targeting Tumor Microenvironment for Cancer Therapy. Int. J. Mol. Sci. 2019, 20, 840. [CrossRef] [PubMed]

10. Lim, Z.-F.; Ma, P.C. Emerging Insights of Tumor Heterogeneity and Drug Resistance Mechanisms in Lung Cancer Targeted Therapy. J. Hematol. Oncol. 2019, 12, 134. [CrossRef]

11. Baliu-Piqué, M.; Pandiella, A.; Ocana, A. Breast Cancer Heterogeneity and Response to Novel Therapeutics. Cancers 2020, 12, 3271. [CrossRef]

12. Bonin, S.; Stanta, G. Pre-Analytics and Tumor Heterogeneity. New Biotechnol. 2020, 55, 30-35. [CrossRef]

13. Davnall, F.; Yip, C.S.P.; Ljungqvist, G.; Selmi, M.; Ng, F.; Sanghera, B.; Ganeshan, B.; Miles, K.A.; Cook, G.J.; Goh, V. Assessment of Tumor Heterogeneity: An Emerging Imaging Tool for Clinical Practice? Insights Imaging 2012, 3, 573-589. [CrossRef]

14. Fass, L. Imaging and Cancer: A Review. Mol. Oncol. 2008, 2, 115-152. [CrossRef]

15. Emaminejad, N.; Qian, W.; Guan, Y.; Tan, M.; Qiu, Y.; Liu, H.; Zheng, B. Fusion of Quantitative Image and Genomic Biomarkers to Improve Prognosis Assessment of Early Stage Lung Cancer Patients. IEEE Trans. Biomed. Eng. 2016, 63, 1034-1043. [CrossRef]

16. Popovici, V.; Budinská, E.; Dušek, L.; Kozubek, M.; Bosman, F. Image-Based Surrogate Biomarkers for Molecular Subtypes of Colorectal Cancer. Bioinformatics 2017, 33, 2002-2009. [CrossRef]

17. Scalco, E.; Rizzo, G. Texture Analysis of Medical Images for Radiotherapy Applications. Br. J. Radiol. 2016, 90. [CrossRef] [PubMed]

18. Aerts, H.J.W.L.; Velazquez, E.R.; Leijenaar, R.T.H.; Parmar, C.; Grossmann, P.; Carvalho, S.; Cavalho, S.; Bussink, J.; Monshouwer, R.; Haibe-Kains, B.; et al. Decoding Tumor Phenotype by Noninvasive Imaging Using a Quantitative Radiomics Approach. Nat. Commun. 2014, 5, 4006. [CrossRef] [PubMed]

19. Trotman, J.; Luminari, S.; Boussetta, S.; Versari, A.; Dupuis, J.; Tychyj, C.; Marcheselli, L.; Berriolo-Riedinger, A.; Franceschetto, A.; Julian, A.; et al. Prognostic Value of PET-CT after First-Line Therapy in Patients with Follicular Lymphoma: A Pooled Analysis of Central Scan Review in Three Multicentre Studies. Lancet Haematol. 2014, 1, e17-e27. [CrossRef]

20. Szyszko, T.A.; Cook, G.J.R. PET/CT and PET/MRI in Head and Neck Malignancy. Clin. Radiol. 2018, 73, 60-69. [CrossRef]

21. Al-Jahdali, H.; Khan, A.N.; Loutfi, S.; Al-Harbi, A.S. Guidelines for the Role of FDG-PET/CT in Lung Cancer Management. J. Infect. Public Health 2012, 5 (Suppl. S1), S35-S40. [CrossRef]

22. Krause, B.J.; Schwarzenböck, S.; Souvatzoglou, M. FDG PET and PET/CT. Recent Results Cancer Res. 2013, 187, 351-369. [CrossRef]

23. Chicklore, S.; Goh, V.; Siddique, M.; Roy, A.; Marsden, P.K.; Cook, G.J.R. Quantifying Tumor Heterogeneity in ${ }^{18}$ F-FDG PET/CT Imaging by Texture Analysis. Eur. J. Nucl. Med. Mol. Imaging 2013, 40, 133-140. [CrossRef] [PubMed]

24. Fonti, R.; Conson, M.; Del Vecchio, S. PET/CT in Radiation Oncology. Semin. Oncol. 2019, 46, 202-209. [CrossRef] [PubMed]

25. Miller, T.R.; Pinkus, E.; Dehdashti, F.; Grigsby, P.W. Improved Prognostic Value of ${ }^{18}$ F-FDG PET Using a Simple Visual Analysis of Tumor Characteristics in Patients with Cervical Cancer. J. Nucl. Med. 2003, 44, 192-197. [PubMed]

26. Avanzo, M.; Stancanello, J.; El Naqa, I. Beyond Imaging: The Promise of Radiomics. Phys. Med. 2017, 38, 122-139. [CrossRef] [PubMed]

27. Kumar, V.; Gu, Y.; Basu, S.; Berglund, A.; Eschrich, S.A.; Schabath, M.B.; Forster, K.; Aerts, H.J.W.L.; Dekker, A.; Fenstermacher, D.; et al. Radiomics: The Process and the Challenges. Magn. Reson. Imaging 2012, 30, 1234-1248. [CrossRef]

28. Fujima, N.; Hirata, K.; Shiga, T.; Yasuda, K.; Onimaru, R.; Tsuchiya, K.; Kano, S.; Mizumachi, T.; Homma, A.; Kudo, K.; et al. Semi-Quantitative Analysis of Pre-Treatment Morphological and Intratumoral Characteristics Using ${ }^{18}$ F-Fluorodeoxyglucose Positron-Emission Tomography as Predictors of Treatment Outcome in Nasal and Paranasal Squamous Cell Carcinoma. Quant. Imaging Med. Surg. 2018, 8, 788-795. [CrossRef] [PubMed]

29. Joo Hyun, O.; Lodge, M.A.; Wahl, R.L. Practical PERCIST: A Simplified Guide to PET Response Criteria in Solid Tumors 1.0. Radiology 2016, 280, 576-584. [CrossRef]

30. Parekh, V.; Jacobs, M.A. Radiomics: A New Application from Established Techniques. Expert Rev. Precis. Med. Drug Dev. 2016, 1, 207-226. [CrossRef] 
31. Gillies, R.J.; Kinahan, P.E.; Hricak, H. Radiomics: Images Are More than Pictures, They Are Data. Radiology 2016, $278,563-577$. [CrossRef] [PubMed]

32. Lambin, P.; Rios-Velazquez, E.; Leijenaar, R.; Carvalho, S.; van Stiphout, R.G.P.M.; Granton, P.; Zegers, C.M.L.; Gillies, R.; Boellard, R.; Dekker, A.; et al. Radiomics: Extracting More Information from Medical Images Using Advanced Feature Analysis. Eur. J. Cancer 2012, 48, 441-446. [CrossRef] [PubMed]

33. Lubner, M.G.; Smith, A.D.; Sandrasegaran, K.; Sahani, D.V.; Pickhardt, P.J. CT Texture Analysis: Definitions, Applications, Biologic Correlates, and Challenges. RadioGraphics 2017, 37, 1483-1503. [CrossRef]

34. Larroza, A.; Bodí, V.; Moratal, D. Texture Analysis in Magnetic Resonance Imaging: Review and Considerations for Future Applications. In Assessment of Cellular and Organ Function and Dysfunction using Direct and Derived MRI Methodologies; Constantinides, C., Ed.; InTech: London, UK, 2016; ISBN 978-953-51-2722-2.

35. Bailly, C.; Bodet-Milin, C.; Bourgeois, M.; Gouard, S.; Ansquer, C.; Barbaud, M.; Sébille, J.-C.; Chérel, M.; Kraeber-Bodéré, F.; Carlier, T. Exploring Tumor Heterogeneity Using PET Imaging: The Big Picture. Cancers 2019, 11, 1282. [CrossRef] [PubMed]

36. Hatt, M.; Tixier, F.; Visvikis, D.; Cheze Le Rest, C. Radiomics in PET/CT: More Than Meets the Eye? J. Nucl. Med. 2017, 58, 365-366. [CrossRef] [PubMed]

37. Tixier, F.; Hatt, M.; Valla, C.; Fleury, V.; Lamour, C.; Ezzouhri, S.; Ingrand, P.; Perdrisot, R.; Visvikis, D.; Le Rest, C.C. Visual versus Quantitative Assessment of Intratumor ${ }^{18}$ F-FDG PET Uptake Heterogeneity: Prognostic Value in Non-Small Cell Lung Cancer. J. Nucl. Med. 2014, 55, 1235-1241. [CrossRef]

38. Haralick, R.M.; Shanmugam, K.; Dinstein, I. Textural Features for Image Classification. IEEE Trans. Syst. Man Cybern. 1973, 6, 610-621. [CrossRef]

39. Amadasun, M.; King, R. Textural Features Corresponding to Textural Properties. IEEE Trans. Syst. Man Cybern. 1989, 19, 1264-1274. [CrossRef]

40. Alic, L.; Niessen, W.J.; Veenland, J.F. Quantification of Heterogeneity as a Biomarker in Tumor Imaging: A Systematic Review. PLoS ONE 2014, 9, e110300. [CrossRef]

41. Materka, A.; Strzelecki, M. Texture Analysis Methods-A Review; COST B11 Report; Technical University of Lodz, Institute of Electronics: Lodz, Poland, 1998; 33p.

42. Castellano, G.; Bonilha, L.; Li, L.M.; Cendes, F. Texture Analysis of Medical Images. Clin. Radiol. 2004, 59, 1061-1069. [CrossRef]

43. Alobaidli, S.; McQuaid, S.; South, C.; Prakash, V.; Evans, P.; Nisbet, A. The Role of Texture Analysis in Imaging as an Outcome Predictor and Potential Tool in Radiotherapy Treatment Planning. Br. J. Radiol. 2014, 87, 20140369. [CrossRef]

44. Mattonen, S.A.; Ward, A.D.; Palma, D.A. Pulmonary Imaging after Stereotactic Radiotherapy—Does RECIST Still Apply? Br. J. Radiol. 2016, 89. [CrossRef] [PubMed]

45. Lu, W.; Wang, J.; Zhang, H.H. Computerized PET/CT Image Analysis in the Evaluation of Tumor Response to Therapy. Br. J. Radiol. 2015, 88, 20140625. [CrossRef] [PubMed]

46. Hatt, M.; Tixier, F.; Pierce, L.; Kinahan, P.E.; Le Rest, C.C.; Visvikis, D. Characterization of PET/CT Images Using Texture Analysis: The Past, the Present ... Any Future? Eur. J. Nucl. Med. Mol. Imaging 2017, 44, 151-165. [CrossRef] [PubMed]

47. Silva-Rodríguez, J.; Tsoumpas, C.; Domínguez-Prado, I.; Pardo-Montero, J.; Ruibal, Á.; Aguiar, P. Impact and Correction of the Bladder Uptake on ${ }^{18}$ F-FCH PET Quantification: A Simulation Study Using the XCAT2 Phantom. Phys. Med. Biol. 2016, 61, 758. [CrossRef] [PubMed]

48. Boellaard, R.; Krak, N.C.; Hoekstra, O.S.; Lammertsma, A.A. Effects of Noise, Image Resolution, and ROI Definition on the Accuracy of Standard Uptake Values: A Simulation Study. J. Nucl. Med. 2004, 45, 1519-1527. [PubMed]

49. Silva-Rodríguez, J.; Aguiar, P.; Domínguez-Prado, I.; Fierro, P.; Ruibal, Á. Simulated FDG-PET Studies for the Assessment of SUV Quantification Methods. Rev. Esp. Med. Nucl. Imagen Mol. 2015, 34, 13-18. [PubMed]

50. Depeursinge, A.; Foncubierta-Rodriguez, A.; Van De Ville, D.; Müller, H. Three-Dimensional Solid Texture Analysis in Biomedical Imaging: Review and Opportunities. Med. Image Anal. 2014, 18, 176-196. [CrossRef]

51. Altman, D.G.; Lausen, B.; Sauerbrei, W.; Schumacher, M. Dangers of Using "Optimal” Cutpoints in the Evaluation of Prognostic Factors. J. Natl. Cancer Inst. 1994, 86, 829-835. [CrossRef] [PubMed]

52. Chalkidou, A.; O'Doherty, M.J.; Marsden, P.K. False Discovery Rates in PET and CT Studies with Texture Features: A Systematic Review. PLoS ONE 2015, 10, e0124165. [CrossRef]

53. Yan, J.; Chu-Shern, J.L.; Loi, H.Y.; Khor, L.K.; Sinha, A.K.; Quek, S.T.; Tham, I.W.K.; Townsend, D. Impact of Image Reconstruction Settings on Texture Features in ${ }^{18}$ F-FDG PET. J. Nucl. Med. 2015, 56, 1667-1673. [CrossRef]

54. Moon, S.H.; Kim, J.; Joung, J.-G.; Cha, H.; Park, W.-Y.; Ahn, J.S.; Ahn, M.-J.; Park, K.; Choi, J.Y.; Lee, K.-H.; et al. Correlations between Metabolic Texture Features, Genetic Heterogeneity, and Mutation Burden in Patients with Lung Cancer. Eur. J. Nucl. Med. Mol. Imaging 2019, 46, 446-454. [CrossRef]

55. Scrivener, M.; de Jong, E.E.C.; van Timmeren, J.E.; Pieters, T.; Ghaye, B.; Geets, X. Radiomics Applied to Lung Cancer: A Review. Transl. Cancer Res. 2016, 5, 398-409. [CrossRef]

56. Han, S.; Woo, S.; Suh, C.H.; Kim, Y.J.; Oh, J.S.; Lee, J.J. A Systematic Review of the Prognostic Value of Texture Analysis in ${ }^{18}$ F-FDG PET in Lung Cancer. Ann. Nucl. Med. 2018, 32, 602-610. [CrossRef] [PubMed]

57. Jensen, G.L.; Yost, C.M.; Mackin, D.S.; Fried, D.V.; Zhou, S.; Court, L.E.; Gomez, D.R. Prognostic Value of Combining a Quantitative Image Feature from Positron Emission Tomography with Clinical Factors in Oligometastatic Non-Small Cell Lung Cancer. Radiother. Oncol. 2018, 126, 362-367. [CrossRef] [PubMed] 
58. Kirienko, M.; Cozzi, L.; Antunovic, L.; Lozza, L.; Fogliata, A.; Voulaz, E.; Rossi, A.; Chiti, A.; Sollini, M. Prediction of Disease-Free Survival by the PET/CT Radiomic Signature in Non-Small Cell Lung Cancer Patients Undergoing Surgery. Eur. J. Nucl. Med. Mol. Imaging 2018, 45, 207-217. [CrossRef]

59. Lemarignier, C.; Martineau, A.; Teixeira, L.; Vercellino, L.; Espie, M.; Merlet, P.; Groheux, D. Correlation between Tumor Characteristics, SUV Measurements, Metabolic Tumor Volume, TLG and Textural Features Assessed with ${ }^{18}$ F-FDG PET in a Large Cohort of Oestrogen Receptor-Positive Breast Cancer Patients. Eur. J. Nucl. Med. Mol. Imaging 2017, 44. [CrossRef] [PubMed]

60. Orlhac, F.; Soussan, M.; Maisonobe, J.-A.; Garcia, C.A.; Vanderlinden, B.; Buvat, I. Tumor Texture Analysis in ${ }^{18}$ F-FDG PET: Relationships between Texture Parameters, Histogram Indices, Standardized Uptake Values, Metabolic Volumes, and Total Lesion Glycolysis. J. Nucl. Med. 2014, 55, 414-422. [CrossRef] [PubMed]

61. Brooks, F.J.; Grigsby, P.W. The Effect of Small Tumor Volumes on Studies of Intratumoral Heterogeneity of Tracer Uptake. J. Nucl. Med. 2014, 55, 37-42. [CrossRef] [PubMed]

62. Hatt, M.; Majdoub, M.; Vallières, M.; Tixier, F.; Le Rest, C.C.; Groheux, D.; Hindié, E.; Martineau, A.; Pradier, O.; Hustinx, R.; et al. ${ }^{18}$ F-FDG PET Uptake Characterization through Texture Analysis: Investigating the Complementary Nature of Heterogeneity and Functional Tumor Volume in a Multi-Cancer Site Patient Cohort. J. Nucl. Med. 2015, 56, 38-44. [CrossRef] [PubMed]

63. Piñeiro-Fiel, M.; Moscoso, A.; Lado-Cacheiro, L.; Pombo-Pasín, M.; Rey-Bretal, D.; Gómez-Lado, N.; Mondelo-García, C.; SilvaRodríguez, J.; Pubul, V.; Sánchez, M.; et al. Is FDG-PET Texture Analysis Related to Intratumor Biological Heterogeneity in Lung Cancer? Eur. Radiol. 2020. [CrossRef]

64. Zwanenburg, A.; Vallières, M.; Abdalah, M.A.; Aerts, H.J.W.L.; Andrearczyk, V.; Apte, A.; Ashrafinia, S.; Bakas, S.; Beukinga, R.J.; Boellaard, R.; et al. The Image Biomarker Standardization Initiative: Standardized Quantitative Radiomics for High-Throughput Image-Based Phenotyping. Radiology 2020, 295, 328-338. [CrossRef] [PubMed]

65. PRISMA. Available online: http:/ / prisma-statement.org/PRISMAStatement/Checklist (accessed on 25 November 2020).

66. Papanikolaou, N.; Matos, C.; Koh, D.M. How to Develop a Meaningful Radiomic Signature for Clinical Use in Oncologic Patients. Cancer Imaging 2020, 20, 33. [CrossRef]

67. Chen, S.; Harmon, S.; Perk, T.; Li, X.; Chen, M.; Li, Y.; Jeraj, R. Using Neighborhood Gray Tone Difference Matrix Texture Features on Dual Time Point PET/CT Images to Differentiate Malignant from Benign FDG-Avid Solitary Pulmonary Nodules. Cancer Imaging 2019, 19, 56. [CrossRef]

68. Nakajo, M.; Jinguji, M.; Aoki, M.; Tani, A.; Sato, M.; Yoshiura, T. The Clinical Value of Texture Analysis of Dual-Time-Point ${ }^{18}$ F-FDG-PET/CT Imaging to Differentiate between ${ }^{18}$ F-FDG-Avid Benign and Malignant Pulmonary Lesions. Eur. Radiol. 2020, 30, 1759-1769. [CrossRef]

69. Soufi, M.; Kamali-Asl, A.; Geramifar, P.; Rahmim, A. A Novel Framework for Automated Segmentation and Labeling of Homogeneous Versus Heterogeneous Lung Tumors in $\left[{ }^{18}\right.$ F]FDG-PET Imaging. Mol. Imaging Biol. 2017, 19, 456-468. [CrossRef] [PubMed]

70. Zhao, J.; Ji, G.; Qiang, Y.; Han, X.; Pei, B.; Shi, Z. A New Method of Detecting Pulmonary Nodules with PET/CT Based on an Improved Watershed Algorithm. PLoS ONE 2015, 10, e0123694. [CrossRef]

71. Zhang, J.; Ma, G.; Cheng, J.; Song, S.; Zhang, Y.; Shi, L.Q. Diagnostic Classification of Solitary Pulmonary Nodules Using Support Vector Machine Model Based on 2-[ ${ }^{18}$ F]Fluoro-2-Deoxy-D-Glucose PET/Computed Tomography Texture Features. Nucl. Med. Commun. 2020, 41, 560-566. [CrossRef]

72. Gao, X.; Chu, C.; Li, Y.; Lu, P.; Wang, W.; Liu, W.; Yu, L. The Method and Efficacy of Support Vector Machine Classifiers Based on Texture Features and Multi-Resolution Histogram from (18)F-FDG PET-CT Images for the Evaluation of Mediastinal Lymph Nodes in Patients with Lung Cancer. Eur. J. Radiol. 2015, 84, 312-317. [CrossRef]

73. Mattonen, S.A.; Davidzon, G.A.; Bakr, S.; Echegaray, S.; Leung, A.N.C.; Vasanawala, M.; Horng, G.; Napel, S.; Nair, V.S. [ ${ }^{18}$ F] FDG Positron Emission Tomography (PET) Tumor and Penumbra Imaging Features Predict Recurrence in Non-Small Cell Lung Cancer. Tomography 2019, 5, 145-153. [CrossRef] [PubMed]

74. Palumbo, B.; Bianconi, F.; Palumbo, I.; Fravolini, M.L.; Minestrini, M.; Nuvoli, S.; Stazza, M.L.; Rondini, M.; Spanu, A. Value of Shape and Texture Features from ${ }^{18}$ F-FDG PET/CT to Discriminate between Benign and Malignant Solitary Pulmonary Nodules: An Experimental Evaluation. Diagnostics 2020, 10, 696. [CrossRef] [PubMed]

75. Du, D.; Gu, J.; Chen, X.; Lv, W.; Feng, Q.; Rahmim, A.; Wu, H.; Lu, L. Integration of PET/CT Radiomics and Semantic Features for Differentiation between Active Pulmonary Tuberculosis and Lung Cancer. Mol. Imaging Biol. 2020. [CrossRef]

76. Chen, S.; Harmon, S.; Perk, T.; Li, X.; Chen, M.; Li, Y.; Jeraj, R. Diagnostic Classification of Solitary Pulmonary Nodules Using Dual Time ${ }^{18}$ F-FDG PET/CT Image Texture Features in Granuloma-Endemic Regions. Sci. Rep. 2017, 7, 9370. [CrossRef]

77. Wang, H.; Zhou, Z.; Li, Y.; Chen, Z.; Lu, P.; Wang, W.; Liu, W.; Yu, L. Comparison of Machine Learning Methods for Classifying Mediastinal Lymph Node Metastasis of Non-Small Cell Lung Cancer from ${ }^{18}$ F-FDG PET/CT Images. EJNMMI Res. $2017,7,11$. [CrossRef] [PubMed]

78. Markel, D.; Caldwell, C.; Alasti, H.; Soliman, H.; Ung, Y.; Lee, J.; Sun, A. Automatic Segmentation of Lung Carcinoma Using 3D Texture Features in 18-FDG PET/CT. Int. J. Mol. Imaging 2013, 2013, 980769. [CrossRef]

79. Kirienko, M.; Cozzi, L.; Rossi, A.; Voulaz, E.; Antunovic, L.; Fogliata, A.; Chiti, A.; Sollini, M. Ability of FDG PET and CT Radiomics Features to Differentiate between Primary and Metastatic Lung Lesions. Eur. J. Nucl. Med. Mol. Imaging 2018, 45, 1649-1660. [CrossRef] 
80. Hu, Y.; Zhao, X.; Zhang, J.; Han, J.; Dai, M. Value of ${ }^{18}$ F-FDG PET/CT Radiomic Features to Distinguish Solitary Lung Adenocarcinoma from Tuberculosis. Eur. J. Nucl. Med. Mol. Imaging 2021, 48, 231-240. [CrossRef]

81. Bashir, U.; Foot, O.; Wise, O.; Siddique, M.M.; Mclean, E.; Bille, A.; Goh, V.; Cook, G.J. Investigating the Histopathologic Correlates of ${ }^{18}$ F-FDG PET Heterogeneity in Non-Small-Cell Lung Cancer. Nucl. Med. Commun. 2018, 39, 1197-1206. [CrossRef] [PubMed]

82. Wu, J.; Lian, C.; Ruan, S.; Mazur, T.R.; Mutic, S.; Anastasio, M.A.; Grigsby, P.W.; Vera, P.; Li, H. Treatment Outcome Prediction for Cancer Patients Based on Radiomics and Belief Function Theory. IEEE Trans. Radiat. Plasma Med. Sci. 2019, 3, 216-224. [CrossRef]

83. Takeda, K.; Takanami, K.; Shirata, Y.; Yamamoto, T.; Takahashi, N.; Ito, K.; Takase, K.; Jingu, K. Clinical Utility of Texture Analysis of ${ }^{18}$ F-FDG PET/CT in Patients with Stage I Lung Cancer Treated with Stereotactic Body Radiotherapy. J. Radiat. Res. 2017, 58, 862-869. [CrossRef]

84. Vaidya, M.; Creach, K.M.; Frye, J.; Dehdashti, F.; Bradley, J.D.; El Naqa, I. Combined PET/CT Image Characteristics for Radiotherapy Tumor Response in Lung Cancer. Radiother. Oncol. 2012, 102, 239-245. [CrossRef]

85. Valentinuzzi, D.; Vrankar, M.; Boc, N.; Ahac, V.; Zupancic, Z.; Unk, M.; Skalic, K.; Zagar, I.; Studen, A.; Simoncic, U.; et al. $\left[{ }^{18}\right.$ F]FDG PET Immunotherapy Radiomics Signature (IRADIOMICS) Predicts Response of Non-Small-Cell Lung Cancer Patients Treated with Pembrolizumab. Radiol. Oncol. 2020, 54, 285-294. [CrossRef]

86. Ha, S.; Choi, H.; Cheon, G.J.; Kang, K.W.; Chung, J.-K.; Kim, E.E.; Lee, D.S. Autoclustering of Non-Small Cell Lung Carcinoma Subtypes on (18)F-FDG PET Using Texture Analysis: A Preliminary Result. Nucl. Med. Mol. Imaging 2014, 48, 278-286. [CrossRef] [PubMed]

87. Astaraki, M.; Wang, C.; Buizza, G.; Toma-Dasu, I.; Lazzeroni, M.; Smedby, Ö. Early Survival Prediction in Non-Small Cell Lung Cancer from PET/CT Images Using an Intra-Tumor Partitioning Method. Phys. Med. 2019, 60, 58-65. [CrossRef]

88. Buizza, G.; Toma-Dasu, I.; Lazzeroni, M.; Paganelli, C.; Riboldi, M.; Chang, Y.; Smedby, Ö.; Wang, C. Early Tumor Response Prediction for Lung Cancer Patients Using Novel Longitudinal Pattern Features from Sequential PET/CT Image Scans. Phys. Med. 2018, 54, 21-29. [CrossRef] [PubMed]

89. Kim, B.S.; Kang, J.; Jun, S.; Kim, H.; Pak, K.; Kim, G.H.; Heo, H.J.; Kim, Y.H. Association between Immunotherapy Biomarkers and Glucose Metabolism from F-18 FDG PET. Eur. Rev. Med. Pharm. Sci. 2020, 24, 8288-8295. [CrossRef]

90. Liu, W.; Sun, X.; Qi, Y.; Jia, X.; Huang, Y.; Liu, N.; Chen, J.; Yuan, S. Integrated Texture Parameter of ${ }^{18}$ F-FDG PET May Be a Stratification Factor for the Survival of Nonoperative Patients with Locally Advanced Non-Small-Cell Lung Cancer. Nucl. Med. Commun. 2018, 39, 732-740. [CrossRef] [PubMed]

91. Van Gómez López, O.; García Vicente, A.M.; Honguero Martínez, A.F.; Soriano Castrejón, A.M.; Jiménez Londoño, G.A.; Udias, J.M.; León Atance, P. Heterogeneity in $\left[{ }^{18}\right.$ F]Fluorodeoxyglucose Positron Emission Tomography/Computed Tomography of NonSmall Cell Lung Carcinoma and Its Relationship to Metabolic Parameters and Pathologic Staging. Mol. Imaging 2014, 13. [CrossRef]

92. Pyka, T.; Bundschuh, R.A.; Andratschke, N.; Mayer, B.; Specht, H.M.; Papp, L.; Zsótér, N.; Essler, M. Textural Features in Pre-Treatment [F18]-FDG-PET/CT Are Correlated with Risk of Local Recurrence and Disease-Specific Survival in Early Stage NSCLC Patients Receiving Primary Stereotactic Radiation Therapy. Radiat. Oncol. 2015, 10, 100. [CrossRef]

93. Cook, G.J.R.; O’Brien, M.E.; Siddique, M.; Chicklore, S.; Loi, H.Y.; Sharma, B.; Punwani, R.; Bassett, P.; Goh, V.; Chua, S. Non-Small Cell Lung Cancer Treated with Erlotinib: Heterogeneity of (18)F-FDG Uptake at PET-Association with Treatment Response and Prognosis. Radiology 2015, 276, 883-893. [CrossRef]

94. Orlhac, F.; Soussan, M.; Chouahnia, K.; Martinod, E.; Buvat, I. ${ }^{18}$ F-FDG PET-Derived Textural Indices Reflect Tissue-Specific Uptake Pattern in Non-Small Cell Lung Cancer. PLoS ONE 2015, 10, e0145063. [CrossRef] [PubMed]

95. Nair, J.K.R.; Saeed, U.A.; McDougall, C.C.; Sabri, A.; Kovacina, B.; Raidu, B.V.S.; Khokhar, R.A.; Probst, S.; Hirsh, V.; Chankowsky, J.; et al. Radiogenomic Models Using Machine Learning Techniques to Predict EGFR Mutations in Non-Small Cell Lung Cancer. Can. Assoc. Radiol. J. 2021, 72, 109-119. [CrossRef] [PubMed]

96. Cook, G.J.R.; Yip, C.; Siddique, M.; Goh, V.; Chicklore, S.; Roy, A.; Marsden, P.; Ahmad, S.; Landau, D. Are Pretreatment ${ }^{18}$ F-FDG PET Tumor Textural Features in Non-Small Cell Lung Cancer Associated with Response and Survival after Chemoradiotherapy? J. Nucl. Med. 2013, 54, 19-26. [CrossRef]

97. Nakajo, M.; Jinguji, M.; Shinaji, T.; Aoki, M.; Tani, A.; Nakabeppu, Y.; Nakajo, M.; Sato, M.; Yoshiura, T. A Pilot Study of Texture Analysis of Primary Tumor $\left[{ }^{18}\right.$ F]FDG Uptake to Predict Recurrence in Surgically Treated Patients with Non-Small Cell Lung Cancer. Mol. Imaging Biol. 2019, 21, 771-780. [CrossRef]

98. Polverari, G.; Ceci, F.; Bertaglia, V.; Reale, M.L.; Rampado, O.; Gallio, E.; Passera, R.; Liberini, V.; Scapoli, P.; Arena, V.; et al. ${ }^{18}$ F-FDG Pet Parameters and Radiomics Features Analysis in Advanced Nsclc Treated with Immunotherapy as Predictors of Therapy Response and Survival. Cancers 2020, 12, 1163. [CrossRef]

99. Dong, X.; Sun, X.; Sun, L.; Maxim, P.G.; Xing, L.; Huang, Y.; Li, W.; Wan, H.; Zhao, X.; Xing, L.; et al. Early Change in Metabolic Tumor Heterogeneity during Chemoradiotherapy and Its Prognostic Value for Patients with Locally Advanced Non-Small Cell Lung Cancer. PLoS ONE 2016, 11, e0157836. [CrossRef]

100. Lovinfosse, P.; Janvary, Z.L.; Coucke, P.; Jodogne, S.; Bernard, C.; Hatt, M.; Visvikis, D.; Jansen, N.; Duysinx, B.; Hustinx, R. FDG PET/CT Texture Analysis for Predicting the Outcome of Lung Cancer Treated by Stereotactic Body Radiation Therapy. Eur. J. Nucl. Med. Mol. Imaging 2016, 43, 1453-1460. [CrossRef]

101. Harmon, S.; Seder, C.W.; Chen, S.; Traynor, A.; Jeraj, R.; Blasberg, J.D. Quantitative FDG PET/CT May Help Risk-Stratify Early-Stage Non-Small Cell Lung Cancer Patients at Risk for Recurrence Following Anatomic Resection. J. Thorac. Dis. 2019, 11, 1106-1116. [CrossRef] [PubMed] 
102. Dissaux, G.; Visvikis, D.; Da-Ano, R.; Pradier, O.; Chajon, E.; Barillot, I.; Duvergé, L.; Masson, I.; Abgral, R.; Santiago Ribeiro, M.-J.; et al. Pretreatment ${ }^{18}$ F-FDG PET/CT Radiomics Predict Local Recurrence in Patients Treated with Stereotactic Body Radiotherapy for Early-Stage Non-Small Cell Lung Cancer: A Multicentric Study. J. Nucl. Med. 2020, 61, 814-820. [CrossRef]

103. Karacavus, S.; Yılmaz, B.; Tasdemir, A.; Kayaaltı, Ö.; Kaya, E.; İçer, S.; Ayyıldız, O. Can Laws Be a Potential PET Image Texture Analysis Approach for Evaluation of Tumor Heterogeneity and Histopathological Characteristics in NSCLC? J. Digit. Imaging 2018, 31, 210-223. [CrossRef] [PubMed]

104. Hao, H.; Zhou, Z.; Li, S.; Maquilan, G.; Folkert, M.R.; Iyengar, P.; Westover, K.D.; Albuquerque, K.; Liu, F.; Choy, H.; et al. Shell Feature: A New Radiomics Descriptor for Predicting Distant Failure after Radiotherapy in Non-Small Cell Lung Cancer and Cervix Cancer. Phys. Med. Biol. 2018, 63, 095007. [CrossRef]

105. Pavic, M.; Bogowicz, M.; Kraft, J.; Vuong, D.; Mayinger, M.; Kroeze, S.G.C.; Friess, M.; Frauenfelder, T.; Andratschke, N.; Huellner, M.; et al. FDG PET versus CT Radiomics to Predict Outcome in Malignant Pleural Mesothelioma Patients. EJNMMI Res. 2020, 10, 81. [CrossRef]

106. Shao, X.; Niu, R.; Shao, X.; Jiang, Z.; Wang, Y. Value of ${ }^{18}$ F-FDG PET/CT-Based Radiomics Model to Distinguish the Growth Patterns of Early Invasive Lung Adenocarcinoma Manifesting as Ground-Glass Opacity Nodules. EJNMMI Res. 2020, 10, 80. [CrossRef]

107. Li, H.; Galperin-Aizenberg, M.; Pryma, D.; Simone, C.B.; Fan, Y. Unsupervised Machine Learning of Radiomic Features for Predicting Treatment Response and Overall Survival of Early Stage Non-Small Cell Lung Cancer Patients Treated with Stereotactic Body Radiation Therapy. Radiother. Oncol. 2018, 129, 218-226. [CrossRef]

108. Wu, J.; Aguilera, T.; Shultz, D.; Gudur, M.; Rubin, D.L.; Loo, B.W.; Diehn, M.; Li, R. Early-Stage Non-Small Cell Lung Cancer: Quantitative Imaging Characteristics of (18)F Fluorodeoxyglucose PET/CT Allow Prediction of Distant Metastasis. Radiology 2016, 281, 270-278. [CrossRef] [PubMed]

109. Koh, Y.W.; Park, S.Y.; Hyun, S.H.; Lee, S.J. Associations between PET Textural Features and GLUT1 Expression, and the Prognostic Significance of Textural Features in Lung Adenocarcinoma. Anticancer Res. 2018, 38, 1067-1071. [CrossRef] [PubMed]

110. Tseng, H.-H.; Luo, Y.; Cui, S.; Chien, J.-T.; Ten Haken, R.K.; Naqa, I.E. Deep Reinforcement Learning for Automated Radiation Adaptation in Lung Cancer. Med. Phys. 2017, 44, 6690-6705. [CrossRef]

111. Li, X.; Yin, G.; Zhang, Y.; Dai, D.; Liu, J.; Chen, P.; Zhu, L.; Ma, W.; Xu, W. Predictive Power of a Radiomic Signature Based on ${ }^{18}$ F-FDG PET/CT Images for EGFR Mutational Status in NSCLC. Front. Oncol. 2019, 9, 1062. [CrossRef]

112. Desseroit, M.-C.; Visvikis, D.; Tixier, F.; Majdoub, M.; Perdrisot, R.; Guillevin, R.; Cheze Le Rest, C.; Hatt, M. Development of a Nomogram Combining Clinical Staging with (18)F-FDG PET/CT Image Features in Non-Small-Cell Lung Cancer Stage I-III. Eur. J. Nucl. Med. Mol. Imaging 2016, 43, 1477-1485. [CrossRef]

113. Luo, Y.; McShan, D.L.; Matuszak, M.M.; Ray, D.; Lawrence, T.S.; Jolly, S.; Kong, F.-M.; Ten Haken, R.K.; El Naqa, I. A Multiobjective Bayesian Networks Approach for Joint Prediction of Tumor Local Control and Radiation Pneumonitis in Nonsmall-Cell Lung Cancer (NSCLC) for Response-Adapted Radiotherapy. Med. Phys. 2018. [CrossRef]

114. Afshar, P.; Mohammadi, A.; Tyrrell, P.N.; Cheung, P.; Sigiuk, A.; Plataniotis, K.N.; Nguyen, E.T.; Oikonomou, A. Deep LearningBased Radiomics for the Time-to-Event Outcome Prediction in Lung Cancer. Sci. Rep. 2020, 10, 12366. [CrossRef]

115. Liu, Q.; Sun, D.; Li, N.; Kim, J.; Feng, D.; Huang, G.; Wang, L.; Song, S. Predicting EGFR Mutation Subtypes in Lung Adenocarcinoma Using ${ }^{18}$ F-FDG PET/CT Radiomic Features. Transl. Lung Cancer Res. 2020, 9, 549-562. [CrossRef]

116. Oikonomou, A.; Khalvati, F.; Tyrrell, P.N.; Haider, M.A.; Tarique, U.; Jimenez-Juan, L.; Tjong, M.C.; Poon, I.; Eilaghi, A.; Ehrlich, L.; et al. Radiomics Analysis at PET/CT Contributes to Prognosis of Recurrence and Survival in Lung Cancer Treated with Stereotactic Body Radiotherapy. Sci. Rep. 2018, 8, 4003. [CrossRef] [PubMed]

117. Koh, Y.W.; Lee, D.; Lee, S.J. Intratumoral Heterogeneity as Measured Using the Tumor-Stroma Ratio and PET Texture Analyses in Females with Lung Adenocarcinomas Differs from That of Males with Lung Adenocarcinomas or Squamous Cell Carcinomas. Medicine 2019, 98, e14876. [CrossRef]

118. Yang, B.; Ji, H.-S.; Zhou, C.-S.; Dong, H.; Ma, L.; Ge, Y.-Q.; Zhu, C.-H.; Tian, J.-H.; Zhang, L.-J.; Zhu, H.; et al. 18 FFluorodeoxyglucose Positron Emission Tomography/Computed Tomography-Based Radiomic Features for Prediction of Epidermal Growth Factor Receptor Mutation Status and Prognosis in Patients with Lung Adenocarcinoma. Transl. Lung Cancer Res. 2020, 9, 563-574. [CrossRef] [PubMed]

119. Park, S.; Ha, S.; Lee, S.-H.; Paeng, J.C.; Keam, B.; Kim, T.M.; Kim, D.-W.; Heo, D.S. Intratumoral Heterogeneity Characterized by Pretreatment PET in Non-Small Cell Lung Cancer Patients Predicts Progression-Free Survival on EGFR Tyrosine Kinase Inhibitor. PLoS ONE 2018, 13, e0189766. [CrossRef] [PubMed]

120. Koyasu, S.; Nishio, M.; Isoda, H.; Nakamoto, Y.; Togashi, K. Usefulness of Gradient Tree Boosting for Predicting Histological Subtype and EGFR Mutation Status of Non-Small Cell Lung Cancer on ${ }^{18}$ F FDG-PET/CT. Ann. Nucl. Med. 2020, 34, 49-57. [CrossRef]

121. Ohri, N.; Duan, F.; Snyder, B.S.; Wei, B.; Machtay, M.; Alavi, A.; Siegel, B.A.; Johnson, D.W.; Bradley, J.D.; DeNittis, A.; et al. Pretreatment ${ }^{18}$ F-FDG PET Textural Features in Locally Advanced Non-Small Cell Lung Cancer: Secondary Analysis of ACRIN 6668/RTOG 0235. J. Nucl. Med. 2016, 57, 842-848. [CrossRef] [PubMed]

122. Mattonen, S.A.; Davidzon, G.A.; Benson, J.; Leung, A.N.C.; Vasanawala, M.; Horng, G.; Shrager, J.B.; Napel, S.; Nair, V.S. Bone Marrow and Tumor Radiomics at ${ }^{18}$ F-FDG PET/CT: Impact on Outcome Prediction in Non-Small Cell Lung Cancer. Radiology 2019, 293, 451-459. [CrossRef] 
123. Yang, B.; Zhong, J.; Zhong, J.; Ma, L.; Li, A.; Ji, H.; Zhou, C.; Duan, S.; Wang, Q.; Zhu, C.; et al. Development and Validation of a Radiomics Nomogram Based on ${ }^{18}$ F-Fluorodeoxyglucose Positron Emission Tomography/Computed Tomography and Clinicopathological Factors to Predict the Survival Outcomes of Patients with Non-Small Cell Lung Cancer. Front. Oncol. 2020, 10, 1042. [CrossRef]

124. Yip, S.S.F.; Kim, J.; Coroller, T.P.; Parmar, C.; Velazquez, E.R.; Huynh, E.; Mak, R.H.; Aerts, H.J.W.L. Associations Between Somatic Mutations and Metabolic Imaging Phenotypes in Non-Small Cell Lung Cancer. J. Nucl. Med. 2017, 58, 569-576. [CrossRef]

125. Arshad, M.A.; Thornton, A.; Lu, H.; Tam, H.; Wallitt, K.; Rodgers, N.; Scarsbrook, A.; McDermott, G.; Cook, G.J.; Landau, D.; et al. Discovery of Pre-Therapy 2-Deoxy-2-18 F-Fluoro-D-Glucose Positron Emission Tomography-Based Radiomics Classifiers of Survival Outcome in Non-Small-Cell Lung Cancer Patients. Eur. J. Nucl. Med. Mol. Imaging 2019, 46, 455-466. [CrossRef]

126. Konert, T.; Everitt, S.; La Fontaine, M.D.; van de Kamer, J.B.; MacManus, M.P.; Vogel, W.V.; Callahan, J.; Sonke, J.-J. Robust, Independent and Relevant Prognostic ${ }^{18}$ F-Fluorodeoxyglucose Positron Emission Tomography Radiomics Features in Non-Small Cell Lung Cancer: Are There Any? PLoS ONE 2020, 15, e0228793. [CrossRef]

127. Jiang, M.; Sun, D.; Guo, Y.; Guo, Y.; Xiao, J.; Wang, L.; Yao, X. Assessing PD-L1 Expression Level by Radiomic Features From PET/CT in Nonsmall Cell Lung Cancer Patients: An Initial Result. Acad. Radiol. 2020, 27, 171-179. [CrossRef] [PubMed]

128. Carvalho, S.; Leijenaar, R.T.H.; Troost, E.G.C.; van Timmeren, J.E.; Oberije, C.; van Elmpt, W.; de Geus-Oei, L.-F.; Bussink, J.; Lambin, P. ${ }^{18}$ F-Fluorodeoxyglucose Positron-Emission Tomography (FDG-PET)-Radiomics of Metastatic Lymph Nodes and Primary Tumor in Non-Small Cell Lung Cancer (NSCLC)—A Prospective Externally Validated Study. PLoS ONE 2018, 13, e0192859. [CrossRef] [PubMed]

129. Han, Y.; Ma, Y.; Wu, Z.; Zhang, F.; Zheng, D.; Liu, X.; Tao, L.; Liang, Z.; Yang, Z.; Li, X.; et al. Histologic Subtype Classification of Non-Small Cell Lung Cancer Using PET/CT Images. Eur. J. Nucl. Med. Mol. Imaging 2020. [CrossRef] [PubMed]

130. Dong, X.; Xing, L.; Wu, P.; Fu, Z.; Wan, H.; Li, D.; Yin, Y.; Sun, X.; Yu, J. Three-Dimensional Positron Emission Tomography Image Texture Analysis of Esophageal Squamous Cell Carcinoma: Relationship between Tumor ${ }^{18}$ F-Fluorodeoxyglucose Uptake Heterogeneity, Maximum Standardized Uptake Value, and Tumor Stage. Nucl. Med. Commun. 2013, 34, 40-46. [CrossRef]

131. Liao, K.Y.-K.; Chiu, C.-C.; Chiang, W.-C.; Chiou, Y.-R.; Zhang, G.; Yang, S.-N.; Huang, T.-C. Radiomics Features Analysis of PET Images in Oropharyngeal and Hypopharyngeal Cancer. Medicine 2019, 98, e15446. [CrossRef]

132. Du, D.; Feng, H.; Lv, W.; Ashrafinia, S.; Yuan, Q.; Wang, Q.; Yang, W.; Feng, Q.; Chen, W.; Rahmim, A.; et al. Machine Learning Methods for Optimal Radiomics-Based Differentiation between Recurrence and Inflammation: Application to Nasopharyngeal Carcinoma Post-Therapy PET/CT Images. Mol. Imaging Biol. 2020, 22, 730-738. [CrossRef]

133. Chen, L.; Zhou, Z.; Sher, D.; Zhang, Q.; Shah, J.; Pham, N.-L.; Jiang, S.; Wang, J. Combining Many-Objective Radiomics and 3D Convolutional Neural Network through Evidential Reasoning to Predict Lymph Node Metastasis in Head and Neck Cancer. Phys. Med. Biol. 2019, 64, 075011. [CrossRef]

134. Baiocco, S.; Sah, B.-R.; Mallia, A.; Kelly-Morland, C.; Neji, R.; Stirling, J.J.; Jeljeli, S.; Bevilacqua, A.; Cook, G.J.R.; Goh, V. Exploratory Radiomic Features from Integrated ${ }^{18}$ F-Fluorodeoxyglucose Positron Emission Tomography/Magnetic Resonance Imaging Are Associated with Contemporaneous Metastases in Oesophageal/Gastroesophageal Cancer. Eur. J. Nucl. Med. Mol. Imaging 2019, 46, 1478-1484. [CrossRef]

135. Ma, C.; Li, D.; Yin, Y.; Cao, J. Comparison of Characteristics of ${ }^{18}$ F-Fluorodeoxyglucose and ${ }^{18}$ F-Fluorothymidine PET during Staging of Esophageal Squamous Cell Carcinoma. Nucl. Med. Commun. 2015, 36, 1181-1186. [CrossRef] [PubMed]

136. Wu, W.-J.; Li, Z.-Y.; Dong, S.; Liu, S.-M.; Zheng, L.; Huang, M.-W.; Zhang, J.-G. Texture Analysis of Pretreatment [ ${ }^{18}$ F]FDG PET/CT for the Prognostic Prediction of Locally Advanced Salivary Gland Carcinoma Treated with Interstitial Brachytherapy. EJNMMI Res. 2019, 9, 89. [CrossRef]

137. Wong, C.-K.; Chan, S.-C.; Ng, S.-H.; Hsieh, C.-H.; Cheng, N.-M.; Yen, T.-C.; Liao, C.-T. Textural Features on ${ }^{18}$ F-FDG PET/CT and Dynamic Contrast-Enhanced MR Imaging for Predicting Treatment Response and Survival of Patients with Hypopharyngeal Carcinoma. Medicine 2019, 98, e16608. [CrossRef]

138. Foley, K.G.; Hills, R.K.; Berthon, B.; Marshall, C.; Parkinson, C.; Lewis, W.G.; Crosby, T.D.L.; Spezi, E.; Roberts, S.A. Development and Validation of a Prognostic Model Incorporating Texture Analysis Derived from Standardised Segmentation of PET in Patients with Oesophageal Cancer. Eur. Radiol. 2018, 28, 428-436. [CrossRef]

139. Guezennec, C.; Robin, P.; Orlhac, F.; Bourhis, D.; Delcroix, O.; Gobel, Y.; Rousset, J.; Schick, U.; Salaün, P.-Y.; Abgral, R. Prognostic Value of Textural Indices Extracted from Pretherapeutic 18-F FDG-PET/CT in Head and Neck Squamous Cell Carcinoma. Head Neck 2019, 41, 495-502. [CrossRef] [PubMed]

140. Tan, S.; Kligerman, S.; Chen, W.; Lu, M.; Kim, G.; Feigenberg, S.; D’Souza, W.D.; Suntharalingam, M.; Lu, W. Spatial-Temporal $\left[{ }^{18}\right.$ F]FDG-PET Features for Predicting Pathologic Response of Esophageal Cancer to Neoadjuvant Chemoradiation Therapy. Int. J. Radiat. Oncol. Biol. Phys. 2013, 85, 1375-1382. [CrossRef]

141. Tan, S.; Zhang, H.; Zhang, Y.; Chen, W.; D'Souza, W.D.; Lu, W. Predicting Pathologic Tumor Response to Chemoradiotherapy with Histogram Distances Characterizing Longitudinal Changes in ${ }^{18}$ F-FDG Uptake Patterns. Med. Phys. 2013, 40, 101707. [CrossRef]

142. Yu, H.; Caldwell, C.; Mah, K.; Mozeg, D. Coregistered FDG PET/CT-Based Textural Characterization of Head and Neck Cancer for Radiation Treatment Planning. IEEE Trans. Med. Imaging 2009, 28, 374-383. [CrossRef]

143. Oh, J.S.; Kang, B.C.; Roh, J.-L.; Kim, J.S.; Cho, K.-J.; Lee, S.-W.; Kim, S.-B.; Choi, S.-H.; Nam, S.Y.; Kim, S.Y. Intratumor Textural Heterogeneity on Pretreatment (18)F-FDG PET Images Predicts Response and Survival After Chemoradiotherapy for Hypopharyngeal Cancer. Ann. Surg. Oncol. 2015, 22, 2746-2754. [CrossRef] 
144. Ulrich, E.J.; Menda, Y.; Boles Ponto, L.L.; Anderson, C.M.; Smith, B.J.; Sunderland, J.J.; Graham, M.M.; Buatti, J.M.; Beichel, R.R. FLT PET Radiomics for Response Prediction to Chemoradiation Therapy in Head and Neck Squamous Cell Cancer. Tomography 2019, 5, 161-169. [CrossRef]

145. Sörensen, A.; Carles, M.; Bunea, H.; Majerus, L.; Stoykow, C.; Nicolay, N.H.; Wiedenmann, N.E.; Vaupel, P.; Meyer, P.T.; Grosu, A.L.; et al. Textural Features of Hypoxia PET Predict Survival in Head and Neck Cancer during Chemoradiotherapy. Eur. J. Nucl. Med. Mol. Imaging 2020, 47, 1056-1064. [CrossRef]

146. Xiong, J.; Yu, W.; Ma, J.; Ren, Y.; Fu, X.; Zhao, J. The Role of PET-Based Radiomic Features in Predicting Local Control of Esophageal Cancer Treated with Concurrent Chemoradiotherapy. Sci. Rep. 2018, 8, 9902. [CrossRef]

147. Kroenke, M.; Hirata, K.; Gafita, A.; Watanabe, S.; Okamoto, S.; Magota, K.; Shiga, T.; Kuge, Y.; Tamaki, N. Voxel Based Comparison and Texture Analysis of ${ }^{18}$ F-FDG and ${ }^{18}$ F-FMISO PET of Patients with Head-and-Neck Cancer. PLoS ONE 2019, 14, e0213111. [CrossRef]

148. Tixier, F.; Le Rest, C.C.; Hatt, M.; Albarghach, N.; Pradier, O.; Metges, J.-P.; Corcos, L.; Visvikis, D. Intratumor Heterogeneity Characterized by Textural Features on Baseline ${ }^{18}$ F-FDG PET Images Predicts Response to Concomitant Radiochemotherapy in Esophageal Cancer. J. Nucl. Med. 2011, 52, 369-378. [CrossRef]

149. Chen, Y.-H.; Lue, K.-H.; Chu, S.-C.; Chang, B.-S.; Wang, L.-Y.; Liu, D.-W.; Liu, S.-H.; Chao, Y.-K.; Chan, S.-C. Combining the Radiomic Features and Traditional Parameters of ${ }^{18}$ F-FDG PET with Clinical Profiles to Improve Prognostic Stratification in Patients with Esophageal Squamous Cell Carcinoma Treated with Neoadjuvant Chemoradiotherapy and Surgery. Ann. Nucl. Med. 2019, 33, 657-670. [CrossRef]

150. Choi, J.W.; Lee, D.; Hyun, S.H.; Han, M.; Kim, J.-H.; Lee, S.J. Intratumoral Heterogeneity Measured Using FDG PET and MRI Is Associated with Tumor-Stroma Ratio and Clinical Outcome in Head and Neck Squamous Cell Carcinoma. Clin. Radiol. 2017, 72, 482-489. [CrossRef]

151. Yip, S.S.F.; Coroller, T.P.; Sanford, N.N.; Huynh, E.; Mamon, H.; Aerts, H.J.W.L.; Berbeco, R.I. Use of Registration-Based Contour Propagation in Texture Analysis for Esophageal Cancer Pathologic Response Prediction. Phys. Med. Biol. 2016, 61, 906-922. [CrossRef] [PubMed]

152. Tixier, F.; Cheze-le-Rest, C.; Schick, U.; Simon, B.; Dufour, X.; Key, S.; Pradier, O.; Aubry, M.; Hatt, M.; Corcos, L.; et al. Transcriptomics in Cancer Revealed by Positron Emission Tomography Radiomics. Sci. Rep. 2020, 10, 5660. [CrossRef]

153. Nakajo, M.; Jinguji, M.; Nakabeppu, Y.; Nakajo, M.; Higashi, R.; Fukukura, Y.; Sasaki, K.; Uchikado, Y.; Natsugoe, S.; Yoshiura, T. Texture Analysis of ${ }^{18}$ F-FDG PET/CT to Predict Tumor Response and Prognosis of Patients with Esophageal Cancer Treated by Chemoradiotherapy. Eur. J. Nucl. Med. Mol. Imaging 2017, 44, 206-214. [CrossRef]

154. Dong, X.; Wu, P.; Sun, X.; Li, W.; Wan, H.; Yu, J.; Xing, L. Intra-Tumor ${ }^{18}$ F-FDG Uptake Heterogeneity Decreases the Reliability on Target Volume Definition with Positron Emission Tomography/Computed Tomography Imaging. J. Med. Imaging Radiat. Oncol. 2015, 59, 338-345. [CrossRef]

155. Lin, H.-C.; Chan, S.-C.; Cheng, N.-M.; Liao, C.-T.; Hsu, C.-L.; Wang, H.-M.; Lin, C.-Y.; Chang, J.T.-C.; Ng, S.-H.; Yang, L.-Y.; et al. Pretreatment ${ }^{18}$ F-FDG PET/CT Texture Parameters Provide Complementary Information to Epstein-Barr Virus DNA Titers in Patients with Metastatic Nasopharyngeal Carcinoma. Oral Oncol. 2020, 104, 104628. [CrossRef]

156. Chen, R.-Y.; Lin, Y.-C.; Shen, W.-C.; Hsieh, T.-C.; Yen, K.-Y.; Chen, S.-W.; Kao, C.-H. Associations of Tumor PD-1 Ligands, Immunohistochemical Studies, and Textural Features in ${ }^{18}$ F-FDG PET in Squamous Cell Carcinoma of the Head and Neck. Sci. Rep. 2018, 8, 105. [CrossRef]

157. Yip, S.S.F.; Coroller, T.P.; Sanford, N.N.; Mamon, H.; Aerts, H.J.W.L.; Berbeco, R.I. Relationship between the Temporal Changes in Positron-Emission-Tomography-Imaging-Based Textural Features and Pathologic Response and Survival in Esophageal Cancer Patients. Front. Oncol. 2016, 6, 72. [CrossRef] [PubMed]

158. Fujima, N.; Hirata, K.; Shiga, T.; Li, R.; Yasuda, K.; Onimaru, R.; Tsuchiya, K.; Kano, S.; Mizumachi, T.; Homma, A.; et al. Integrating Quantitative Morphological and Intratumoral Textural Characteristics in FDG-PET for the Prediction of Prognosis in Pharynx Squamous Cell Carcinoma Patients. Clin. Radiol. 2018, 73, 1059.e1-1059.e8. [CrossRef]

159. Chen, S.-W.; Shen, W.-C.; Lin, Y.-C.; Chen, R.-Y.; Hsieh, T.-C.; Yen, K.-Y.; Kao, C.-H. Correlation of Pretreatment ${ }^{18}$ F-FDG PET Tumor Textural Features with Gene Expression in Pharyngeal Cancer and Implications for Radiotherapy-Based Treatment Outcomes. Eur. J. Nucl. Med. Mol. Imaging 2017, 44, 567-580. [CrossRef]

160. Desbordes, P.; Ruan, S.; Modzelewski, R.; Pineau, P.; Vauclin, S.; Gouel, P.; Michel, P.; Di Fiore, F.; Vera, P.; Gardin, I. Predictive Value of Initial FDG-PET Features for Treatment Response and Survival in Esophageal Cancer Patients Treated with ChemoRadiation Therapy Using a Random Forest Classifier. PLoS ONE 2017, 12, e0173208. [CrossRef]

161. Cheng, N.-M.; Fang, Y.-H.D.; Chang, J.T.-C.; Huang, C.-G.; Tsan, D.-L.; Ng, S.-H.; Wang, H.-M.; Lin, C.-Y.; Liao, C.-T.; Yen, T.-C. Textural Features of Pretreatment ${ }^{18}$ F-FDG PET/CT Images: Prognostic Significance in Patients with Advanced T-Stage Oropharyngeal Squamous Cell Carcinoma. J. Nucl. Med. 2013, 54, 1703-1709. [CrossRef] [PubMed]

162. Beukinga, R.J.; Hulshoff, J.B.; Mul, V.E.M.; Noordzij, W.; Kats-Ugurlu, G.; Slart, R.H.J.A.; Plukker, J.T.M. Prediction of Response to Neoadjuvant Chemotherapy and Radiation Therapy with Baseline and Restaging ${ }^{18}$ F-FDG PET Imaging Biomarkers in Patients with Esophageal Cancer. Radiology 2018, 287, 983-992. [CrossRef] [PubMed]

163. Cheng, N.-M.; Hsieh, C.-E.; Fang, Y.-H.D.; Liao, C.-T.; Ng, S.-H.; Wang, H.-M.; Chou, W.-C.; Lin, C.-Y.; Yen, T.-C. Development and Validation of a Prognostic Model Incorporating [ ${ }^{18}$ F]FDG PET/CT Radiomics for Patients with Minor Salivary Gland Carcinoma. EJNMMI Res. 2020, 10, 74. [CrossRef] 
164. Crispin-Ortuzar, M.; Apte, A.; Grkovski, M.; Oh, J.H.; Lee, N.Y.; Schöder, H.; Humm, J.L.; Deasy, J.O. Predicting Hypoxia Status Using a Combination of Contrast-Enhanced Computed Tomography and $\left[{ }^{18} \mathrm{~F}\right]$-Fluorodeoxyglucose Positron Emission Tomography Radiomics Features. Radiother. Oncol. 2018, 127, 36-42. [CrossRef]

165. Cheng, N.-M.; Hsieh, C.-E.; Liao, C.-T.; Ng, S.-H.; Wang, H.-M.; Fang, Y.-H.D.; Chou, W.-C.; Lin, C.-Y.; Yen, T.-C. Prognostic Value of Tumor Heterogeneity and SUVmax of Pretreatment ${ }^{18}$ F-FDG PET/CT for Salivary Gland Carcinoma with High-Risk Histology. Clin. Nucl. Med. 2019, 44, 351-358. [CrossRef]

166. Cheng, N.-M.; Fang, Y.-H.D.; Lee, L.; Chang, J.T.-C.; Tsan, D.-L.; Ng, S.-H.; Wang, H.-M.; Liao, C.-T.; Yang, L.-Y.; Hsu, C.-H.; et al. Zone-Size Nonuniformity of ${ }^{18}$ F-FDG PET Regional Textural Features Predicts Survival in Patients with Oropharyngeal Cancer. Eur. J. Nucl. Med. Mol. Imaging 2015, 42, 419-428. [CrossRef] [PubMed]

167. Feliciani, G.; Fioroni, F.; Grassi, E.; Bertolini, M.; Rosca, A.; Timon, G.; Galaverni, M.; Iotti, C.; Versari, A.; Iori, M.; et al. Radiomic Profiling of Head and Neck Cancer: ${ }^{18}$ F-FDG PET Texture Analysis as Predictor of Patient Survival. Contrast Media Mol. Imaging 2018, 2018, 3574310. [CrossRef]

168. Beukinga, R.J.; Hulshoff, J.B.; van Dijk, L.V.; Muijs, C.T.; Burgerhof, J.G.M.; Kats-Ugurlu, G.; Slart, R.H.J.A.; Slump, C.H.; Mul, V.E.M.; Plukker, J.T.M. Predicting Response to Neoadjuvant Chemoradiotherapy in Esophageal Cancer with Textural Features Derived from Pretreatment ${ }^{18}$ F-FDG PET/CT Imaging. J. Nucl. Med. 2017, 58, 723-729. [CrossRef]

169. Feng, Q.; Liang, J.; Wang, L.; Niu, J.; Ge, X.; Pang, P.; Ding, Z. Radiomics Analysis and Correlation With Metabolic Parameters in Nasopharyngeal Carcinoma Based on PET/MR Imaging. Front. Oncol. 2020, 10, 1619. [CrossRef]

170. Chan, S.-C.; Chang, K.-P.; Fang, Y.-H.D.; Tsang, N.-M.; Ng, S.-H.; Hsu, C.-L.; Liao, C.-T.; Yen, T.-C. Tumor Heterogeneity Measured on F-18 Fluorodeoxyglucose Positron Emission Tomography/Computed Tomography Combined with Plasma Epstein-Barr Virus Load Predicts Prognosis in Patients with Primary Nasopharyngeal Carcinoma. Laryngoscope 2017, 127, E22-E28. [CrossRef]

171. Ypsilantis, P.-P.; Siddique, M.; Sohn, H.-M.; Davies, A.; Cook, G.; Goh, V.; Montana, G. Predicting Response to Neoadjuvant Chemotherapy with PET Imaging Using Convolutional Neural Networks. PLoS ONE 2015, 10, e0137036. [CrossRef]

172. Lv, W.; Yuan, Q.; Wang, Q.; Ma, J.; Feng, Q.; Chen, W.; Rahmim, A.; Lu, L. Radiomics Analysis of PET and CT Components of PET/CT Imaging Integrated with Clinical Parameters: Application to Prognosis for Nasopharyngeal Carcinoma. Mol. Imaging Biol. 2019, 21, 954-964. [CrossRef]

173. Xu, H.; Lv, W.; Feng, H.; Du, D.; Yuan, Q.; Wang, Q.; Dai, Z.; Yang, W.; Feng, Q.; Ma, J.; et al. Subregional Radiomics Analysis of PET/CT Imaging with Intratumor Partitioning: Application to Prognosis for Nasopharyngeal Carcinoma. Mol. Imaging Biol. 2020, 22, 1414-1426. [CrossRef]

174. Ghosh, S.; Maulik, S.; Chatterjee, S.; Mallick, I.; Chakravorty, N.; Mukherjee, J. Prediction of Survival Outcome Based on Clinical Features and Pretreatment ${ }^{18}$ FDG-PET/CT for HNSCC Patients. Comput. Methods Programs Biomed. 2020, 195, 105669. [CrossRef]

175. Cao, Q.; Li, Y.; Li, Z.; An, D.; Li, B.; Lin, Q. Development and Validation of a Radiomics Signature on Differentially Expressed Features of ${ }^{18}$ F-FDG PET to Predict Treatment Response of Concurrent Chemoradiotherapy in Thoracic Esophagus Squamous Cell Carcinoma. Radiother. Oncol. 2020, 146, 9-15. [CrossRef]

176. Bogowicz, M.; Riesterer, O.; Stark, L.S.; Studer, G.; Unkelbach, J.; Guckenberger, M.; Tanadini-Lang, S. Comparison of PET and CT Radiomics for Prediction of Local Tumor Control in Head and Neck Squamous Cell Carcinoma. Acta Oncol. 2017, 56, 1531-1536. [CrossRef]

177. Martens, R.M.; Koopman, T.; Noij, D.P.; Pfaehler, E.; Übelhör, C.; Sharma, S.; Vergeer, M.R.; Leemans, C.R.; Hoekstra, O.S.; Yaqub, M.; et al. Predictive Value of Quantitative ${ }^{18}$ F-FDG-PET Radiomics Analysis in Patients with Head and Neck Squamous Cell Carcinoma. EJNMMI Res. 2020, 10, 102. [CrossRef] [PubMed]

178. Folkert, M.R.; Setton, J.; Apte, A.P.; Grkovski, M.; Young, R.J.; Schöder, H.; Thorstad, W.L.; Lee, N.Y.; Deasy, J.O.; Oh, J.H. Predictive Modeling of Outcomes Following Definitive Chemoradiotherapy for Oropharyngeal Cancer Based on FDG-PET Image Characteristics. Phys. Med. Biol. 2017, 62, 5327-5343. [CrossRef]

179. Bogowicz, M.; Leijenaar, R.T.H.; Tanadini-Lang, S.; Riesterer, O.; Pruschy, M.; Studer, G.; Unkelbach, J.; Guckenberger, M.; Konukoglu, E.; Lambin, P. Post-Radiochemotherapy PET Radiomics in Head and Neck Cancer-The Influence of Radiomics Implementation on the Reproducibility of Local Control Tumor Models. Radiother. Oncol. 2017, 125, 385-391. [CrossRef]

180. Wang, K.; Zhou, Z.; Wang, R.; Chen, L.; Zhang, Q.; Sher, D.; Wang, J. A Multi-Objective Radiomics Model for the Prediction of Locoregional Recurrence in Head and Neck Squamous Cell Cancer. Med. Phys. 2020, 47, 5392-5400. [CrossRef] [PubMed]

181. Lv, W.; Ashrafinia, S.; Ma, J.; Lu, L.; Rahmim, A. Multi-Level Multi-Modality Fusion Radiomics: Application to PET and CT Imaging for Prognostication of Head and Neck Cancer. IEEE J. Biomed. Health Inf. 2020, 24, 2268-2277. [CrossRef]

182. Vallières, M.; Kay-Rivest, E.; Perrin, L.J.; Liem, X.; Furstoss, C.; Aerts, H.J.W.L.; Khaouam, N.; Nguyen-Tan, P.F.; Wang, C.-S.; Sultanem, K.; et al. Radiomics Strategies for Risk Assessment of Tumor Failure in Head-and-Neck Cancer. Sci. Rep. 2017, 7, 10117. [CrossRef]

183. Haider, S.P.; Zeevi, T.; Baumeister, P.; Reichel, C.; Sharaf, K.; Forghani, R.; Kann, B.H.; Judson, B.L.; Prasad, M.L.; Burtness, B.; et al. Potential Added Value of PET/CT Radiomics for Survival Prognostication beyond AJCC 8th Edition Staging in Oropharyngeal Squamous Cell Carcinoma. Cancers 2020, 12, 1778. [CrossRef]

184. Liu, Z.; Cao, Y.; Diao, W.; Cheng, Y.; Jia, Z.; Peng, X. Radiomics-Based Prediction of Survival in Patients with Head and Neck Squamous Cell Carcinoma Based on Pre- and Post-Treatment ${ }^{18}$ F-PET/CT. Aging 2020, 12, 14593-14619. [CrossRef] [PubMed] 
185. Haider, S.P.; Mahajan, A.; Zeevi, T.; Baumeister, P.; Reichel, C.; Sharaf, K.; Forghani, R.; Kucukkaya, A.S.; Kann, B.H.; Judson, B.L.; et al. PET/CT Radiomics Signature of Human Papilloma Virus Association in Oropharyngeal Squamous Cell Carcinoma. Eur. J. Nucl. Med. Mol. Imaging 2020, 47, 2978-2991. [CrossRef]

186. Ger, R.B.; Zhou, S.; Elgohari, B.; Elhalawani, H.; Mackin, D.M.; Meier, J.G.; Nguyen, C.M.; Anderson, B.M.; Gay, C.; Ning, J.; et al. Radiomics Features of the Primary Tumor Fail to Improve Prediction of Overall Survival in Large Cohorts of CT- and PET-Imaged Head and Neck Cancer Patients. PLoS ONE 2019, 14, e0222509. [CrossRef]

187. Peng, H.; Dong, D.; Fang, M.-J.; Li, L.; Tang, L.-L.; Chen, L.; Li, W.-F.; Mao, Y.-P.; Fan, W.; Liu, L.-Z.; et al. Prognostic Value of Deep Learning PET/CT-Based Radiomics: Potential Role for Future Individual Induction Chemotherapy in Advanced Nasopharyngeal Carcinoma. Clin. Cancer Res. 2019, 25, 4271-4279. [CrossRef] [PubMed]

188. Lee, H.; Lee, D.; Park, S.; Kim, T.S.; Jung, S.-Y.; Lee, S.; Kang, H.S.; Lee, E.S.; Sim, S.H.; Park, I.H.; et al. Predicting Response to Neoadjuvant Chemotherapy in Patients with Breast Cancer: Combined Statistical Modeling Using Clinicopathological Factors and FDG PET/CT Texture Parameters. Clin. Nucl. Med. 2019, 44, 21-29. [CrossRef] [PubMed]

189. Groheux, D.; Martineau, A.; Teixeira, L.; Espié, M.; de Cremoux, P.; Bertheau, P.; Merlet, P.; Lemarignier, C. ${ }^{18}$ FDG-PET/CT for Predicting the Outcome in ER+/HER2- Breast Cancer Patients: Comparison of Clinicopathological Parameters and PET Image-Derived Indices Including Tumor Texture Analysis. Breast Cancer Res. 2017, 19, 3. [CrossRef]

190. Soussan, M.; Orlhac, F.; Boubaya, M.; Zelek, L.; Ziol, M.; Eder, V.; Buvat, I. Relationship between Tumor Heterogeneity Measured on FDG-PET/CT and Pathological Prognostic Factors in Invasive Breast Cancer. PLoS ONE 2014, 9, e94017. [CrossRef]

191. Acar, E.; Turgut, B.; Yiğit, S.; Kaya, G. Comparison of the Volumetric and Radiomics Findings of ${ }^{18}$ F-FDG PET/CT Images with Immunohistochemical Prognostic Factors in Local/Locally Advanced Breast Cancer. Nucl. Med. Commun. 2019, 40, 764-772. [CrossRef]

192. Ou, X.; Wang, J.; Zhou, R.; Zhu, S.; Pang, F.; Zhou, Y.; Tian, R.; Ma, X. Ability of ${ }^{18}$ F-FDG PET/CT Radiomic Features to Distinguish Breast Carcinoma from Breast Lymphoma. Contrast Media Mol. Imaging 2019, 2019, 4507694. [CrossRef]

193. Li, P.; Wang, X.; Xu, C.; Liu, C.; Zheng, C.; Fulham, M.J.; Feng, D.; Wang, L.; Song, S.; Huang, G. ${ }^{18}$ F-FDG PET/CT Radiomic Predictors of Pathologic Complete Response (PCR) to Neoadjuvant Chemotherapy in Breast Cancer Patients. Eur. J. Nucl. Med. Mol. Imaging 2020, 47, 1116-1126. [CrossRef]

194. Ou, X.; Zhang, J.; Wang, J.; Pang, F.; Wang, Y.; Wei, X.; Ma, X. Radiomics Based on 18 F-FDG PET/CT Could Differentiate Breast Carcinoma from Breast Lymphoma Using Machine-Learning Approach: A Preliminary Study. Cancer Med. 2020, 9, 496-506. [CrossRef] [PubMed]

195. Yoon, H.-J.; Kim, Y.; Chung, J.; Kim, B.S. Predicting Neo-Adjuvant Chemotherapy Response and Progression-Free Survival of Locally Advanced Breast Cancer Using Textural Features of Intratumoral Heterogeneity on F-18 FDG PET/CT and DiffusionWeighted MR Imaging. Breast J. 2019, 25, 373-380. [CrossRef]

196. Vogl, W.-D.; Pinker, K.; Helbich, T.H.; Bickel, H.; Grabner, G.; Bogner, W.; Gruber, S.; Bago-Horvath, Z.; Dubsky, P.; Langs, G. Automatic Segmentation and Classification of Breast Lesions through Identification of Informative Multiparametric PET/MRI Features. Eur. Radiol. Exp. 2019, 3, 18. [CrossRef]

197. Chang, C.-C.; Chen, C.-J.; Hsu, W.-L.; Chang, S.-M.; Huang, Y.-F.; Tyan, Y.-C. Prognostic Significance of Metabolic Parameters and Textural Features on ${ }^{18}$ F-FDG PET/CT in Invasive Ductal Carcinoma of Breast. Sci. Rep. 2019, 9, 10946. [CrossRef] [PubMed]

198. Cheng, L.; Zhang, J.; Wang, Y.; Xu, X.; Zhang, Y.; Zhang, Y.; Liu, G.; Cheng, J. Textural Features of ${ }^{18}$ F-FDG PET after Two Cycles of Neoadjuvant Chemotherapy Can Predict PCR in Patients with Locally Advanced Breast Cancer. Ann. Nucl. Med. 2017, 31, 544-552. [CrossRef] [PubMed]

199. Antunovic, L.; De Sanctis, R.; Cozzi, L.; Kirienko, M.; Sagona, A.; Torrisi, R.; Tinterri, C.; Santoro, A.; Chiti, A.; Zelic, R.; et al. PET/CT Radiomics in Breast Cancer: Promising Tool for Prediction of Pathological Response to Neoadjuvant Chemotherapy. Eur. J. Nucl. Med. Mol. Imaging 2019, 46, 1468-1477. [CrossRef]

200. Ha, S.; Park, S.; Bang, J.-I.; Kim, E.-K.; Lee, H.-Y. Metabolic Radiomics for Pretreatment ${ }^{18}$ F-FDG PET/CT to Characterize Locally Advanced Breast Cancer: Histopathologic Characteristics, Response to Neoadjuvant Chemotherapy, and Prognosis. Sci. Rep. 2017, 7, 1556. [CrossRef] [PubMed]

201. Molina-García, D.; García-Vicente, A.M.; Pérez-Beteta, J.; Amo-Salas, M.; Martínez-González, A.; Tello-Galán, M.J.; SorianoCastrejón, Á.; Pérez-García, V.M. Intratumoral Heterogeneity in ${ }^{18}$ F-FDG PET/CT by Textural Analysis in Breast Cancer as a Predictive and Prognostic Subrogate. Ann. Nucl. Med. 2018, 32, 379-388. [CrossRef]

202. Huang, S.-Y.; Franc, B.L.; Harnish, R.J.; Liu, G.; Mitra, D.; Copeland, T.P.; Arasu, V.A.; Kornak, J.; Jones, E.F.; Behr, S.C.; et al. Exploration of PET and MRI Radiomic Features for Decoding Breast Cancer Phenotypes and Prognosis. Npj Breast Cancer 2018, 4, 24. [CrossRef]

203. Moscoso, A.; Ruibal, A.; Dominguez-Prado, I.; Fernández-Ferreiro, A.; Herranz, M.; Albaina, L.; Argibay, S.; Silva-Rodriguez, J.; Pardo-Montero, J.; Aguiar, P. Texture Analysis of High-Resolution Dedicated Breast 18 F-FDG PET Images Correlates with Immunohistochemical Factors and Subtype of Breast Cancer. Eur. J. Nucl. Med. Mol. Imaging 2018, 45, 196-206. [CrossRef]

204. Groheux, D.; Majdoub, M.; Tixier, F.; Le Rest, C.C.; Martineau, A.; Merlet, P.; Espié, M.; de Roquancourt, A.; Hindié, E.; Hatt, M.; et al. Do Clinical, Histological or Immunohistochemical Primary Tumor Characteristics Translate into Different (18)F-FDG PET/CT Volumetric and Heterogeneity Features in Stage II/III Breast Cancer? Eur. J. Nucl. Med. Mol. Imaging 2015, 42, 1682-1691. [CrossRef] 
205. Payan, N.; Presles, B.; Brunotte, F.; Coutant, C.; Desmoulins, I.; Vrigneaud, J.-M.; Cochet, A. Biological Correlates of Tumor Perfusion and Its Heterogeneity in Newly Diagnosed Breast Cancer Using Dynamic First-Pass ${ }^{18}$ F-FDG PET/CT. Eur. J. Nucl. Med. Mol. Imaging 2020, 47, 1103-1115. [CrossRef] [PubMed]

206. Schiano, C.; Franzese, M.; Pane, K.; Garbino, N.; Soricelli, A.; Salvatore, M.; de Nigris, F.; Napoli, C. Hybrid ${ }^{18}$ F-FDG-PET/MRI Measurement of Standardized Uptake Value Coupled with Yin Yang 1 Signature in Metastatic Breast Cancer. A Preliminary Study. Cancers 2019, 11, 1444. [CrossRef] [PubMed]

207. De Bernardi, E.; Buda, A.; Guerra, L.; Vicini, D.; Elisei, F.; Landoni, C.; Fruscio, R.; Messa, C.; Crivellaro, C. Radiomics of the Primary Tumor as a Tool to Improve ${ }^{18}$ F-FDG-PET Sensitivity in Detecting Nodal Metastases in Endometrial Cancer. EJNMMI Res. 2018, 8, 86. [CrossRef] [PubMed]

208. Crivellaro, C.; Landoni, C.; Elisei, F.; Buda, A.; Bonacina, M.; Grassi, T.; Monaco, L.; Giuliani, D.; Gotuzzo, I.; Magni, S.; et al. Combining Positron Emission Tomography/Computed Tomography, Radiomics, and Sentinel Lymph Node Mapping for Nodal Staging of Endometrial Cancer Patients. Int. J. Gynecol. Cancer 2020, 30, 378-382. [CrossRef]

209. Mu, W.; Chen, Z.; Liang, Y.; Shen, W.; Yang, F.; Dai, R.; Wu, N.; Tian, J. Staging of Cervical Cancer Based on Tumor Heterogeneity Characterized by Texture Features on (18)F-FDG PET Images. Phys. Med. Biol. 2015, 60, 5123-5139. [CrossRef]

210. Tsujikawa, T.; Rahman, T.; Yamamoto, M.; Yamada, S.; Tsuyoshi, H.; Kiyono, Y.; Kimura, H.; Yoshida, Y.; Okazawa, H. ${ }^{18}$ F-FDG PET Radiomics Approaches: Comparing and Clustering Features in Cervical Cancer. Ann. Nucl. Med. 2017, 31, 678-685. [CrossRef] [PubMed]

211. Li, K.; Sun, H.; Lu, Z.; Xin, J.; Zhang, L.; Guo, Y.; Guo, Q. Value of [ ${ }^{18}$ F]FDG PET Radiomic Features and VEGF Expression in Predicting Pelvic Lymphatic Metastasis and Their Potential Relationship in Early-Stage Cervical Squamous Cell Carcinoma. Eur. J. Radiol. 2018, 106, 160-166. [CrossRef] [PubMed]

212. Shen, W.-C.; Chen, S.-W.; Liang, J.-A.; Hsieh, T.-C.; Yen, K.-Y.; Kao, C.-H. [18]Fluorodeoxyglucose Positron Emission Tomography for the Textural Features of Cervical Cancer Associated with Lymph Node Metastasis and Histological Type. Eur. J. Nucl. Med. Mol. Imaging 2017, 44, 1721-1731. [CrossRef] [PubMed]

213. Wang, T.; Sun, H.; Guo, Y.; Zou, L. ${ }^{18}$ F-FDG PET/CT Quantitative Parameters and Texture Analysis Effectively Differentiate Endometrial Precancerous Lesion and Early-Stage Carcinoma. Mol. Imaging 2019, 18, 1536012119856965. [CrossRef]

214. Umutlu, L.; Nensa, F.; Demircioglu, A.; Antoch, G.; Herrmann, K.; Forsting, M.; Grueneisen, J.S. Radiomics Analysis of Multiparametric PET/MRI for N- and M-Staging in Patients with Primary Cervical Cancer. RoFo 2020, 192, 754-763. [CrossRef] [PubMed]

215. Ho, K.-C.; Fang, Y.-H.D.; Chung, H.-W.; Yen, T.-C.; Ho, T.-Y.; Chou, H.-H.; Hong, J.-H.; Huang, Y.-T.; Wang, C.-C.; Lai, C.-H. A Preliminary Investigation into Textural Features of Intratumoral Metabolic Heterogeneity in (18)F-FDG PET for Overall Survival Prognosis in Patients with Bulky Cervical Cancer Treated with Definitive Concurrent Chemoradiotherapy. Am. J. Nucl. Med. Mol. Imaging 2016, 6, 166-175.

216. Yang, F.; Thomas, M.A.; Dehdashti, F.; Grigsby, P.W. Temporal Analysis of Intratumoral Metabolic Heterogeneity Characterized by Textural Features in Cervical Cancer. Eur. J. Nucl. Med. Mol. Imaging 2013, 40, 716-727. [CrossRef]

217. Chen, S.-W.; Shen, W.-C.; Hsieh, T.-C.; Liang, J.-A.; Hung, Y.-C.; Yeh, L.-S.; Chang, W.-C.; Lin, W.-C.; Yen, K.-Y.; Kao, C.-H. Textural Features of Cervical Cancers on FDG-PET/CT Associate with Survival and Local Relapse in Patients Treated with Definitive Chemoradiotherapy. Sci. Rep. 2018, 8, 11859. [CrossRef] [PubMed]

218. Roman-Jimenez, G.; Acosta, O.; Leseur, J.; Devillers, A.; Der Sarkissian, H.; Guzman, L.; Grossiord, E.; Ospina, J.-D.; De Crevoisier, R. Random Forests to Predict Tumor Recurrence Following Cervical Cancer Therapy Using Pre- and per-Treatment ${ }^{18}$ F-FDG PET Parameters. Annu. Int. Conf. IEEE Eng. Med. Biol. Soc. 2016, 2016, 2444-2447. [CrossRef] [PubMed]

219. Reuzé, S.; Orlhac, F.; Chargari, C.; Nioche, C.; Limkin, E.; Riet, F.; Escande, A.; Haie-Meder, C.; Dercle, L.; Gouy, S.; et al. Prediction of Cervical Cancer Recurrence Using Textural Features Extracted from ${ }^{18}$ F-FDG PET Images Acquired with Different Scanners. Oncotarget 2017, 8, 43169-43179. [CrossRef] [PubMed]

220. Collarino, A.; Garganese, G.; Fragomeni, S.M.; Pereira Arias-Bouda, L.M.; Ieria, F.P.; Boellaard, R.; Rufini, V.; de Geus-Oei, L.-F.; Scambia, G.; Valdés Olmos, R.A.; et al. Radiomics in Vulvar Cancer: First Clinical Experience Using ${ }^{18}$ F-FDG PET/CT Images. J. Nucl. Med. 2018. [CrossRef] [PubMed]

221. Novikov, M. Multiparametric Quantitative and Texture ${ }^{18}$ F-FDG PET/CT Analysis for Primary Malignant Tumor Grade Differentiation. Eur. Radiol. Exp. 2019, 3, 48. [CrossRef]

222. Lucia, F.; Visvikis, D.; Desseroit, M.-C.; Miranda, O.; Malhaire, J.-P.; Robin, P.; Pradier, O.; Hatt, M.; Schick, U. Prediction of Outcome Using Pretreatment ${ }^{18}$ F-FDG PET/CT and MRI Radiomics in Locally Advanced Cervical Cancer Treated with Chemoradiotherapy. Eur. J. Nucl. Med. Mol. Imaging 2018, 45, 768-786. [CrossRef]

223. Lucia, F.; Visvikis, D.; Vallières, M.; Desseroit, M.-C.; Miranda, O.; Robin, P.; Bonaffini, P.A.; Alfieri, J.; Masson, I.; Mervoyer, A.; et al. External Validation of a Combined PET and MRI Radiomics Model for Prediction of Recurrence in Cervical Cancer Patients Treated with Chemoradiotherapy. Eur. J. Nucl. Med. Mol. Imaging 2019, 46, 864-877. [CrossRef]

224. Aide, N.; Talbot, M.; Fruchart, C.; Damaj, G.; Lasnon, C. Diagnostic and Prognostic Value of Baseline FDG PET/CT Skeletal Textural Features in Diffuse Large B Cell Lymphoma. Eur. J. Nucl. Med. Mol. Imaging 2018, 45, 699-711. [CrossRef] [PubMed]

225. Kong, Z.; Jiang, C.; Zhu, R.; Feng, S.; Wang, Y.; Li, J.; Chen, W.; Liu, P.; Zhao, D.; Ma, W.; et al. ${ }^{18}$ F-FDG-PET-Based Radiomics Features to Distinguish Primary Central Nervous System Lymphoma from Glioblastoma. Neuroimage Clin. $2019,23,101912$. [CrossRef] [PubMed] 
226. Mayerhoefer, M.E.; Riedl, C.C.; Kumar, A.; Dogan, A.; Gibbs, P.; Weber, M.; Staber, P.B.; Huicochea Castellanos, S.; Schöder, H. $\left[{ }^{18} \mathrm{~F}\right]$ FDG-PET/CT Radiomics for Prediction of Bone Marrow Involvement in Mantle Cell Lymphoma: A Retrospective Study in 97 Patients. Cancers 2020, 12, 1138. [CrossRef]

227. Lartizien, C.; Rogez, M.; Niaf, E.; Ricard, F. Computer-Aided Staging of Lymphoma Patients with FDG PET/CT Imaging Based on Textural Information. IEEE J. Biomed. Health Inf. 2014, 18, 946-955. [CrossRef] [PubMed]

228. Li, H.; Xu, C.; Xin, B.; Zheng, C.; Zhao, Y.; Hao, K.; Wang, Q.; Wahl, R.L.; Wang, X.; Zhou, Y. ${ }^{18}$ F-FDG PET/CT Radiomic Analysis with Machine Learning for Identifying Bone Marrow Involvement in the Patients with Suspected Relapsed Acute Leukemia. Theranostics 2019, 9, 4730-4739. [CrossRef]

229. Tatsumi, M.; Isohashi, K.; Matsunaga, K.; Watabe, T.; Kato, H.; Kanakura, Y.; Hatazawa, J. Volumetric and Texture Analysis on FDG PET in Evaluating and Predicting Treatment Response and Recurrence after Chemotherapy in Follicular Lymphoma. Int. J. Clin. Oncol. 2019, 24, 1292-1300. [CrossRef]

230. Ben Bouallègue, F.; Tabaa, Y.A.; Kafrouni, M.; Cartron, G.; Vauchot, F.; Mariano-Goulart, D. Association between Textural and Morphological Tumor Indices on Baseline PET-CT and Early Metabolic Response on Interim PET-CT in Bulky Malignant Lymphomas. Med. Phys. 2017, 44, 4608-4619. [CrossRef]

231. Jamet, B.; Morvan, L.; Nanni, C.; Michaud, A.-V.; Bailly, C.; Chauvie, S.; Moreau, P.; Touzeau, C.; Zamagni, E.; Bodet-Milin, C.; et al. Random Survival Forest to Predict Transplant-Eligible Newly Diagnosed Multiple Myeloma Outcome Including FDG-PET Radiomics: A Combined Analysis of Two Independent Prospective European Trials. Eur. J. Nucl. Med. Mol. Imaging 2020. [CrossRef]

232. Parvez, A.; Tau, N.; Hussey, D.; Maganti, M.; Metser, U. ${ }^{18}$ F-FDG PET/CT Metabolic Tumor Parameters and Radiomics Features in Aggressive Non-Hodgkin's Lymphoma as Predictors of Treatment Outcome and Survival. Ann. Nucl. Med. 2018, 32, 410-416. [CrossRef]

233. Milgrom, S.A.; Elhalawani, H.; Lee, J.; Wang, Q.; Mohamed, A.S.R.; Dabaja, B.S.; Pinnix, C.C.; Gunther, J.R.; Court, L.; Rao, A.; et al. A PET Radiomics Model to Predict Refractory Mediastinal Hodgkin Lymphoma. Sci. Rep. 2019, 9, 1322. [CrossRef]

234. Mayerhoefer, M.E.; Riedl, C.C.; Kumar, A.; Gibbs, P.; Weber, M.; Tal, I.; Schilksy, J.; Schöder, H. Radiomic Features of Glucose Metabolism Enable Prediction of Outcome in Mantle Cell Lymphoma. Eur. J. Nucl. Med. Mol. Imaging 2019, 46, 2760-2769. [CrossRef]

235. Lue, K.-H.; Wu, Y.-F.; Liu, S.-H.; Hsieh, T.-C.; Chuang, K.-S.; Lin, H.-H.; Chen, Y.-H. Prognostic Value of Pretreatment Radiomic Features of ${ }^{18}$ F-FDG PET in Patients With Hodgkin Lymphoma. Clin. Nucl. Med. 2019, 44, e559-e565. [CrossRef]

236. Aide, N.; Fruchart, C.; Nganoa, C.; Gac, A.-C.; Lasnon, C. Baseline ${ }^{18}$ F-FDG PET Radiomic Features as Predictors of 2-Year Event-Free Survival in Diffuse Large B Cell Lymphomas Treated with Immunochemotherapy. Eur. Radiol. 2020, 30, 4623-4632. [CrossRef]

237. Wang, H.; Zhao, S.; Li, L.; Tian, R. Development and Validation of an ${ }^{18}$ F-FDG PET Radiomic Model for Prognosis Prediction in Patients with Nasal-Type Extranodal Natural Killer/T Cell Lymphoma. Eur. Radiol. 2020, 30, 5578-5587. [CrossRef]

238. Sun, Y.; Qiao, X.; Jiang, C.; Liu, S.; Zhou, Z. Texture Analysis Improves the Value of Pretreatment ${ }^{18}$ F-FDG PET/CT in Predicting Interim Response of Primary Gastrointestinal Diffuse Large B-Cell Lymphoma. Contrast Media Mol. Imaging 2020, 2020, 2981585. [CrossRef] [PubMed]

239. Lue, K.-H.; Wu, Y.-F.; Liu, S.-H.; Hsieh, T.-C.; Chuang, K.-S.; Lin, H.-H.; Chen, Y.-H. Intratumor Heterogeneity Assessed by ${ }^{18}$ F-FDG PET/CT Predicts Treatment Response and Survival Outcomes in Patients with Hodgkin Lymphoma. Acad. Radiol. 2020, 27, e183-e192. [CrossRef] [PubMed]

240. Zhou, Y.; Ma, X.-L.; Pu, L.-T.; Zhou, R.-F.; Ou, X.-J.; Tian, R. Prediction of Overall Survival and Progression-Free Survival by the ${ }^{18}$ F-FDG PET/CT Radiomic Features in Patients with Primary Gastric Diffuse Large B-Cell Lymphoma. Contrast Media Mol. Imaging 2019, 2019, 5963607. [CrossRef] [PubMed]

241. Yadav, D.; Shamim, S.A.; Rastogi, S.; Upadhyay, D.M.R.; Pandey, A.K.; Kumar, R. Role of ${ }^{18}$ F-FDG PET/Computed Tomography in Prognostication and Management of Malignant Peripheral Nerve Sheath Tumors. Nucl. Med. Commun. 2020, 41, 924-932. [CrossRef]

242. Uthoff, J.; De Stefano, F.A.; Panzer, K.; Darbro, B.W.; Sato, T.S.; Khanna, R.; Quelle, D.E.; Meyerholz, D.K.; Weimer, J.; Sieren, J.C. Radiomic Biomarkers Informative of Cancerous Transformation in Neurofibromatosis-1 Plexiform Tumors. J. Neuroradiol. 2019, 46, 179-185. [CrossRef]

243. Pyka, T.; Gempt, J.; Hiob, D.; Ringel, F.; Schlegel, J.; Bette, S.; Wester, H.-J.; Meyer, B.; Förster, S. Textural Analysis of PreTherapeutic $\left[{ }^{18}\right.$ F]-FET-PET and Its Correlation with Tumor Grade and Patient Survival in High-Grade Gliomas. Eur. J. Nucl. Med. Mol. Imaging 2016, 43, 133-141. [CrossRef] [PubMed]

244. Lohmann, P.; Stoffels, G.; Ceccon, G.; Rapp, M.; Sabel, M.; Filss, C.P.; Kamp, M.A.; Stegmayr, C.; Neumaier, B.; Shah, N.J.; et al. Radiation Injury vs. Recurrent Brain Metastasis: Combining Textural Feature Radiomics Analysis and Standard Parameters May Increase ${ }^{18}$ F-FET PET Accuracy without Dynamic Scans. Eur. Radiol. 2017, 27, 2916-2927. [CrossRef] [PubMed]

245. Lohmann, P.; Kocher, M.; Ceccon, G.; Bauer, E.K.; Stoffels, G.; Viswanathan, S.; Ruge, M.I.; Neumaier, B.; Shah, N.J.; Fink, G.R.; et al. Combined FET PET/MRI Radiomics Differentiates Radiation Injury from Recurrent Brain Metastasis. Neuroimage Clin. 2018, 20, 537-542. [CrossRef]

246. Wang, K.; Qiao, Z.; Zhao, X.; Li, X.; Wang, X.; Wu, T.; Chen, Z.; Fan, D.; Chen, Q.; Ai, L. Individualized Discrimination of Tumor Recurrence from Radiation Necrosis in Glioma Patients Using an Integrated Radiomics-Based Model. Eur. J. Nucl. Med. Mol. Imaging 2020, 47, 1400-1411. [CrossRef] 
247. Muzi, M.; Wolsztynski, E.; Fink, J.R.; O'Sullivan, J.N.; O’Sullivan, F.; Krohn, K.A.; Mankoff, D.A. Assessment of the Prognostic Value of Radiomic Features in ${ }^{18}$ F-FMISO PET Imaging of Hypoxia in Postsurgery Brain Cancer Patients: Secondary Analysis of Imaging Data from a Single-Center Study and the Multicenter ACRIN 6684 Trial. Tomography 2020, 6, 14-22. [CrossRef]

248. Hotta, M.; Minamimoto, R.; Miwa, K. 11C-Methionine-PET for Differentiating Recurrent Brain Tumor from Radiation Necrosis: Radiomics Approach with Random Forest Classifier. Sci. Rep. 2019, 9, 15666. [CrossRef]

249. Papp, L.; Pötsch, N.; Grahovac, M.; Schmidbauer, V.; Woehrer, A.; Preusser, M.; Mitterhauser, M.; Kiesel, B.; Wadsak, W.; Beyer, T.; et al. Glioma Survival Prediction with Combined Analysis of In Vivo 11C-MET PET Features, Ex Vivo Features, and Patient Features by Supervised Machine Learning. J. Nucl. Med. 2018, 59, 892-899. [CrossRef] [PubMed]

250. Stefano, A.; Comelli, A.; Bravatà, V.; Barone, S.; Daskalovski, I.; Savoca, G.; Sabini, M.G.; Ippolito, M.; Russo, G. A Preliminary PET Radiomics Study of Brain Metastases Using a Fully Automatic Segmentation Method. BMC Bioinform. 2020, 21, 325. [CrossRef] [PubMed]

251. Haubold, J.; Demircioglu, A.; Gratz, M.; Glas, M.; Wrede, K.; Sure, U.; Antoch, G.; Keyvani, K.; Nittka, M.; Kannengiesser, S.; et al. Non-Invasive Tumor Decoding and Phenotyping of Cerebral Gliomas Utilizing Multiparametric ${ }^{18}$ F-FET PET-MRI and MR Fingerprinting. Eur. J. Nucl. Med. Mol. Imaging 2020, 47, 1435-1445. [CrossRef] [PubMed]

252. Lohmann, P.; Lerche, C.; Bauer, E.K.; Steger, J.; Stoffels, G.; Blau, T.; Dunkl, V.; Kocher, M.; Viswanathan, S.; Filss, C.P.; et al. Predicting IDH Genotype in Gliomas Using FET PET Radiomics. Sci. Rep. 2018, 8, 13328. [CrossRef]

253. Qian, J.; Herman, M.G.; Brinkmann, D.H.; Laack, N.N.; Kemp, B.J.; Hunt, C.H.; Lowe, V.; Pafundi, D.H. Prediction of MGMT Status for Glioblastoma Patients Using Radiomics Feature Extraction From ${ }^{18}$ F-DOPA-PET Imaging. Int. J. Radiat. Oncol. Biol. Phys. 2020, 108, 1339-1346. [CrossRef] [PubMed]

254. Kong, Z.; Lin, Y.; Jiang, C.; Li, L.; Liu, Z.; Wang, Y.; Dai, C.; Liu, D.; Qin, X.; Wang, Y.; et al. ${ }^{18}$ F-FDG-PET-Based Radiomics Signature Predicts MGMT Promoter Methylation Status in Primary Diffuse Glioma. Cancer Imaging 2019, 19, 58. [CrossRef]

255. Kong, Z.; Li, J.; Liu, Z.; Liu, Z.; Zhao, D.; Cheng, X.; Li, L.; Lin, Y.; Wang, Y.; Tian, J.; et al. Radiomics Signature Based on FDG-PET Predicts Proliferative Activity in Primary Glioma. Clin. Radiol. 2019, 74, 815.e15-815.e23. [CrossRef] [PubMed]

256. Li, L.; Mu, W.; Wang, Y.; Liu, Z.; Liu, Z.; Wang, Y.; Ma, W.; Kong, Z.; Wang, S.; Zhou, X.; et al. A Non-Invasive Radiomic Method Using ${ }^{18}$ F-FDG PET Predicts Isocitrate Dehydrogenase Genotype and Prognosis in Patients with Glioma. Front. Oncol. 2019, 9, 1183. [CrossRef]

257. Jiang, Y.; Yuan, Q.; Lv, W.; Xi, S.; Huang, W.; Sun, Z.; Chen, H.; Zhao, L.; Liu, W.; Hu, Y.; et al. Radiomic Signature of ${ }^{18}$ F Fluorodeoxyglucose PET/CT for Prediction of Gastric Cancer Survival and Chemotherapeutic Benefits. Theranostics 2018, 8, 5915-5928. [CrossRef] [PubMed]

258. Bang, J.-I.; Ha, S.; Kang, S.-B.; Lee, K.-W.; Lee, H.-S.; Kim, J.-S.; Oh, H.-K.; Lee, H.-Y.; Kim, S.E. Prediction of Neoadjuvant Radiation Chemotherapy Response and Survival Using Pretreatment [(18)F]FDG PET/CT Scans in Locally Advanced Rectal Cancer. Eur. J. Nucl. Med. Mol. Imaging 2016, 43, 422-431. [CrossRef] [PubMed]

259. Lovinfosse, P.; Polus, M.; Van Daele, D.; Martinive, P.; Daenen, F.; Hatt, M.; Visvikis, D.; Koopmansch, B.; Lambert, F.; Coimbra, C.; et al. FDG PET/CT Radiomics for Predicting the Outcome of Locally Advanced Rectal Cancer. Eur. J. Nucl. Med. Mol. Imaging 2018, 45, 365-375. [CrossRef]

260. Brown, P.J.; Zhong, J.; Frood, R.; Currie, S.; Gilbert, A.; Appelt, A.L.; Sebag-Montefiore, D.; Scarsbrook, A. Prediction of Outcome in Anal Squamous Cell Carcinoma Using Radiomic Feature Analysis of Pre-Treatment FDG PET-CT. Eur. J. Nucl. Med. Mol. Imaging 2019, 46, 2790-2799. [CrossRef]

261. Shen, W.-C.; Chen, S.-W.; Wu, K.-C.; Lee, P.-Y.; Feng, C.-L.; Hsieh, T.-C.; Yen, K.-Y.; Kao, C.-H. Predicting Pathological Complete Response in Rectal Cancer after Chemoradiotherapy with a Random Forest Using ${ }^{18}$ F-Fluorodeoxyglucose Positron Emission Tomography and Computed Tomography Radiomics. Ann. Transl. Med. 2020, 8, 207. [CrossRef]

262. Van Helden, E.J.; Vacher, Y.J.L.; van Wieringen, W.N.; van Velden, F.H.P.; Verheul, H.M.W.; Hoekstra, O.S.; Boellaard, R.; Menkevan der Houven van Oordt, C.W. Radiomics Analysis of Pre-Treatment $\left[{ }^{18}\right.$ F]FDG PET/CT for Patients with Metastatic Colorectal Cancer Undergoing Palliative Systemic Treatment. Eur. J. Nucl. Med. Mol. Imaging 2018, 45, 2307-2317. [CrossRef]

263. Nakajo, M.; Kajiya, Y.; Tani, A.; Jinguji, M.; Nakajo, M.; Kitazono, M.; Yoshiura, T. A Pilot Study for Texture Analysis of ${ }^{18}$ F-FDG and ${ }^{18}$ F-FLT-PET/CT to Predict Tumor Recurrence of Patients with Colorectal Cancer Who Received Surgery. Eur. J. Nucl. Med. Mol. Imaging 2017, 44, 2158-2168. [CrossRef]

264. Giannini, V.; Mazzetti, S.; Bertotto, I.; Chiarenza, C.; Cauda, S.; Delmastro, E.; Bracco, C.; Di Dia, A.; Leone, F.; Medico, E.; et al. Predicting Locally Advanced Rectal Cancer Response to Neoadjuvant Therapy with ${ }^{18}$ F-FDG PET and MRI Radiomics Features. Eur. J. Nucl. Med. Mol. Imaging 2019, 46, 878-888. [CrossRef]

265. Chen, S.-W.; Shen, W.-C.; Chen, W.T.-L.; Hsieh, T.-C.; Yen, K.-Y.; Chang, J.-G.; Kao, C.-H. Metabolic Imaging Phenotype Using Radiomics of $\left[{ }^{18}\right.$ F]FDG PET/CT Associated with Genetic Alterations of Colorectal Cancer. Mol. Imaging Biol. 2019, 21, 183-190. [CrossRef]

266. Karahan Şen, N.P.; Aksu, A.; Kaya, G.Ç. Value of Volumetric and Textural Analysis in Predicting the Treatment Response in Patients with Locally Advanced Rectal Cancer. Ann. Nucl. Med. 2020, 34, 960-967. [CrossRef] [PubMed]

267. Lovinfosse, P.; Koopmansch, B.; Lambert, F.; Jodogne, S.; Kustermans, G.; Hatt, M.; Visvikis, D.; Seidel, L.; Polus, M.; Albert, A.; et al. (18)F-FDG PET/CT Imaging in Rectal Cancer: Relationship with the RAS Mutational Status. Br. J. Radiol. 2016, 89, 20160212. [CrossRef] [PubMed] 
268. Zhang, Y.; Cheng, C.; Liu, Z.; Wang, L.; Pan, G.; Sun, G.; Chang, Y.; Zuo, C.; Yang, X. Radiomics Analysis for the Differentiation of Autoimmune Pancreatitis and Pancreatic Ductal Adenocarcinoma in 18 F-FDG PET/CT. Med. Phys. 2019, 46, 4520-4530. [CrossRef] [PubMed]

269. Yue, Y.; Osipov, A.; Fraass, B.; Sandler, H.; Zhang, X.; Nissen, N.; Hendifar, A.; Tuli, R. Identifying Prognostic Intratumor Heterogeneity Using Pre- and Post-Radiotherapy ${ }^{18}$ F-FDG PET Images for Pancreatic Cancer Patients. J. Gastrointest. Oncol. 2017, 8, 127-138. [CrossRef]

270. Lim, C.H.; Cho, Y.S.; Choi, J.Y.; Lee, K.-H.; Lee, J.K.; Min, J.H.; Hyun, S.H. Imaging Phenotype Using ${ }^{18}$ F-Fluorodeoxyglucose Positron Emission Tomography-Based Radiomics and Genetic Alterations of Pancreatic Ductal Adenocarcinoma. Eur. J. Nucl. Med. Mol. Imaging 2020, 47, 2113-2122. [CrossRef] [PubMed]

271. Yoo, M.Y.; Yoon, Y.-S.; Suh, M.S.; Cho, J.Y.; Han, H.-S.; Lee, W.W. Prognosis Prediction of Pancreatic Cancer after Curative Intent Surgery Using Imaging Parameters Derived from F-18 Fluorodeoxyglucose Positron Emission Tomography/Computed Tomography. Medicine 2020, 99, e21829. [CrossRef]

272. Yoo, S.H.; Kang, S.Y.; Cheon, G.J.; Oh, D.-Y.; Bang, Y.-J. Predictive Role of Temporal Changes in Intratumoral Metabolic Heterogeneity During Palliative Chemotherapy in Patients with Advanced Pancreatic Cancer: A Prospective Cohort Study. J. Nucl. Med. 2020, 61, 33-39. [CrossRef]

273. Hyun, S.H.; Kim, H.S.; Choi, S.H.; Choi, D.W.; Lee, J.K.; Lee, K.H.; Park, J.O.; Lee, K.-H.; Kim, B.-T.; Choi, J.Y. Intratumoral Heterogeneity of (18)F-FDG Uptake Predicts Survival in Patients with Pancreatic Ductal Adenocarcinoma. Eur. J. Nucl. Med. Mol. Imaging 2016, 43, 1461-1468. [CrossRef]

274. Toyama, Y.; Hotta, M.; Motoi, F.; Takanami, K.; Minamimoto, R.; Takase, K. Prognostic Value of FDG-PET Radiomics with Machine Learning in Pancreatic Cancer. Sci. Rep. 2020, 10, 17024. [CrossRef] [PubMed]

275. Mori, M.; Passoni, P.; Incerti, E.; Bettinardi, V.; Broggi, S.; Reni, M.; Whybra, P.; Spezi, E.; Vanoli, E.G.; Gianolli, L.; et al. Training and Validation of a Robust PET Radiomic-Based Index to Predict Distant-Relapse-Free-Survival after Radio-Chemotherapy for Locally Advanced Pancreatic Cancer. Radiother. Oncol. 2020, 153, 258-264. [CrossRef]

276. Tsujikawa, T.; Yamamoto, M.; Shono, K.; Yamada, S.; Tsuyoshi, H.; Kiyono, Y.; Kimura, H.; Okazawa, H.; Yoshida, Y. Assessment of Intratumor Heterogeneity in Mesenchymal Uterine Tumor by an ${ }^{18}$ F-FDG PET/CT Texture Analysis. Ann. Nucl. Med. 2017, 31, 752-757. [CrossRef]

277. Xu, R.; Kido, S.; Suga, K.; Hirano, Y.; Tachibana, R.; Muramatsu, K.; Chagawa, K.; Tanaka, S. Texture Analysis on (18)F-FDG PET/CT Images to Differentiate Malignant and Benign Bone and Soft-Tissue Lesions. Ann. Nucl. Med. 2014, 28, 926-935. [CrossRef]

278. Bailly, C.; Leforestier, R.; Campion, L.; Thebaud, E.; Moreau, A.; Kraeber-Bodere, F.; Carlier, T.; Bodet-Milin, C. Prognostic Value of FDG-PET Indices for the Assessment of Histological Response to Neoadjuvant Chemotherapy and Outcome in Pediatric Patients with Ewing Sarcoma and Osteosarcoma. PLoS ONE 2017, 12, e0183841. [CrossRef]

279. Song, H.; Jiao, Y.; Wei, W.; Ren, X.; Shen, C.; Qiu, Z.; Yang, Q.; Wang, Q.; Luo, Q.-Y. Can Pretreatment ${ }^{18}$ F-FDG PET Tumor Texture Features Predict the Outcomes of Osteosarcoma Treated by Neoadjuvant Chemotherapy? Eur. Radiol. 2019, 29, 3945-3954. [CrossRef]

280. Vallières, M.; Freeman, C.R.; Skamene, S.R.; El Naqa, I. A Radiomics Model from Joint FDG-PET and MRI Texture Features for the Prediction of Lung Metastases in Soft-Tissue Sarcomas of the Extremities. Phys. Med. Biol. 2015, 60, 5471-5496. [CrossRef] [PubMed]

281. Jeong, S.Y.; Kim, W.; Byun, B.H.; Kong, C.-B.; Song, W.S.; Lim, I.; Lim, S.M.; Woo, S.-K. Prediction of Chemotherapy Response of Osteosarcoma Using Baseline ${ }^{18}$ F-FDG Textural Features Machine Learning Approaches with PCA. Contrast Media Mol. Imaging 2019, 2019, 3515080. [CrossRef] [PubMed]

282. Sheen, H.; Kim, W.; Byun, B.H.; Kong, C.-B.; Song, W.S.; Cho, W.H.; Lim, I.; Lim, S.M.; Woo, S.-K. Metastasis Risk Prediction Model in Osteosarcoma Using Metabolic Imaging Phenotypes: A Multivariable Radiomics Model. PLoS ONE 2019, 14, e0225242. [CrossRef] [PubMed]

283. Wolsztynski, E.; O’Sullivan, F.; Keyes, E.; O'Sullivan, J.; Eary, J.F. Positron Emission Tomography-Based Assessment of Metabolic Gradient and Other Prognostic Features in Sarcoma. J. Med. Imaging 2018, 5, 024502. [CrossRef] [PubMed]

284. Werner, R.A.; Lapa, C.; Ilhan, H.; Higuchi, T.; Buck, A.K.; Lehner, S.; Bartenstein, P.; Bengel, F.; Schatka, I.; Muegge, D.O.; et al. Survival Prediction in Patients Undergoing Radionuclide Therapy Based on Intratumoral Somatostatin-Receptor Heterogeneity. Oncotarget 2017, 8, 7039-7049. [CrossRef] [PubMed]

285. Werner, R.A.; Ilhan, H.; Lehner, S.; Papp, L.; Zsótér, N.; Schatka, I.; Muegge, D.O.; Javadi, M.S.; Higuchi, T.; Buck, A.K.; et al. Pre-Therapy Somatostatin Receptor-Based Heterogeneity Predicts Overall Survival in Pancreatic Neuroendocrine Tumor Patients Undergoing Peptide Receptor Radionuclide Therapy. Mol. Imaging Biol. 2019, 21, 582-590. [CrossRef] [PubMed]

286. Ansquer, C.; Drui, D.; Mirallié, E.; Renaudin-Autain, K.; Denis, A.; Gimenez-Roqueplo, A.-P.; Leux, C.; Toulgoat, F.; KraeberBodéré, F.; Carlier, T. Usefulness of FDG-PET/CT-Based Radiomics for the Characterization and Genetic Orientation of Pheochromocytomas Before Surgery. Cancers 2020, 12, 2424. [CrossRef]

287. Mapelli, P.; Partelli, S.; Salgarello, M.; Doraku, J.; Pasetto, S.; Rancoita, P.M.V.; Muffatti, F.; Bettinardi, V.; Presotto, L.; Andreasi, V.; et al. Dual Tracer 68Ga-DOTATOC and ${ }^{18}$ F-FDG PET/Computed Tomography Radiomics in Pancreatic Neuroendocrine Neoplasms: An Endearing Tool for Preoperative Risk Assessment. Nucl. Med. Commun. 2020, 41, 896-905. [CrossRef] [PubMed] 
288. Weber, M.; Kessler, L.; Schaarschmidt, B.; Fendler, W.P.; Lahner, H.; Antoch, G.; Umutlu, L.; Herrmann, K.; Rischpler, C. Textural Analysis of Hybrid DOTATOC-PET/MRI and Its Association with Histological Grading in Patients with Liver Metastases from Neuroendocrine Tumors. Nucl. Med. Commun. 2020, 41, 363-369. [CrossRef] [PubMed]

289. Cysouw, M.C.F.; Jansen, B.H.E.; van de Brug, T.; Oprea-Lager, D.E.; Pfaehler, E.; de Vries, B.M.; van Moorselaar, R.J.A.; Hoekstra, O.S.; Vis, A.N.; Boellaard, R. Machine Learning-Based Analysis of $\left[{ }^{18}\right.$ F]DCFPyL PET Radiomics for Risk Stratification in Primary Prostate Cancer. Eur. J. Nucl. Med. Mol. Imaging 2021, 48, 340-349. [CrossRef]

290. Kang, H.; Kim, E.E.; Shokouhi, S.; Tokita, K.; Shin, H.-W. Texture Analysis of F-18 Fluciclovine PET/CT to Predict Biochemically Recurrent Prostate Cancer: Initial Results. Tomography 2020, 6, 301-307. [CrossRef]

291. Zamboglou, C.; Carles, M.; Fechter, T.; Kiefer, S.; Reichel, K.; Fassbender, T.F.; Bronsert, P.; Koeber, G.; Schilling, O.; Ruf, J.; et al. Radiomic Features from PSMA PET for Non-Invasive Intraprostatic Tumor Discrimination and Characterization in Patients with Intermediate- and High-Risk Prostate Cancer-A Comparison Study with Histology Reference. Theranostics 2019, 9, 2595-2605. [CrossRef]

292. Khurshid, Z.; Ahmadzadehfar, H.; Gaertner, F.C.; Papp, L.; Zsóter, N.; Essler, M.; Bundschuh, R.A. Role of Textural Heterogeneity Parameters in Patient Selection for 177Lu-PSMA Therapy via Response Prediction. Oncotarget 2018, 9, 33312-33321. [CrossRef]

293. Ceriani, L.; Milan, L.; Virili, C.; Cascione, L.; Paone, G.; Trimboli, P.; Giovanella, L. Radiomics Analysis of [18F]Fluorodeoxyglucose-Avid Thyroid Incidentalomas Improves Risk Stratification and Selection for Clinical Assessment. Thyroid 2021, 31, 88-95. [CrossRef]

294. Sollini, M.; Cozzi, L.; Pepe, G.; Antunovic, L.; Lania, A.; Di Tommaso, L.; Magnoni, P.; Erba, P.A.; Kirienko, M. [ ${ }^{18}$ F]FDG-PET/CT Texture Analysis in Thyroid Incidentalomas: Preliminary Results. Eur. J. Hybrid Imaging 2017, 1, 3. [CrossRef]

295. Nakajo, M.; Jinguji, M.; Shinaji, T.; Tani, A.; Nakabeppu, Y.; Nakajo, M.; Nakajo, A.; Natsugoe, S.; Yoshiura, T. ${ }^{18}$ F-FDGPET/CT Features of Primary Tumors for Predicting the Risk of Recurrence in Thyroid Cancer after Total Thyroidectomy: Potential Usefulness of Combination of the SUV-Related, Volumetric, and Heterogeneous Texture Parameters. Br. J. Radiol. 2019, 92, 20180620. [CrossRef] [PubMed]

296. Lee, H.S.; Oh, J.S.; Park, Y.S.; Jang, S.J.; Choi, I.S.; Ryu, J.-S. Differentiating the Grades of Thymic Epithelial Tumor Malignancy Using Textural Features of Intratumoral Heterogeneity via (18)F-FDG PET/CT. Ann. Nucl. Med. 2016, 30, 309-319. [CrossRef] [PubMed]

297. Nakajo, M.; Jinguji, M.; Shinaji, T.; Nakajo, M.; Aoki, M.; Tani, A.; Sato, M.; Yoshiura, T. Texture Analysis of ${ }^{18}$ F-FDG PET/CT for Grading Thymic Epithelial Tumors: Usefulness of Combining SUV and Texture Parameters. Br. J. Radiol. 2018, 91, 20170546. [CrossRef]

298. Saadani, H.; van der Hiel, B.; Aalbersberg, E.A.; Zavrakidis, I.; Haanen, J.B.A.G.; Hoekstra, O.S.; Boellaard, R.; Stokkel, M.P.M. Metabolic Biomarker-Based BRAFV600 Mutation Association and Prediction in Melanoma. J. Nucl. Med. 2019, 60, 1545-1552. [CrossRef]

299. Dittrich, D.; Pyka, T.; Scheidhauer, K.; Lütje, S.; Essler, M.; Bundschuh, R.A. Textural Features in FDG-PET/CT Can Predict Outcome in Melanoma Patients to Treatment with Vemurafenib and Ipililumab. Nuklearmedizin 2020, 59, 228-234. [CrossRef] [PubMed]

300. Xu, H.; Guo, W.; Cui, X.; Zhuo, H.; Xiao, Y.; Ou, X.; Zhao, Y.; Zhang, T.; Ma, X. Three-Dimensional Texture Analysis Based on PET/CT Images to Distinguish Hepatocellular Carcinoma and Hepatic Lymphoma. Front. Oncol. 2019, 9, 844. [CrossRef]

301. Blanc-Durand, P.; Van Der Gucht, A.; Jreige, M.; Nicod-Lalonde, M.; Silva-Monteiro, M.; Prior, J.O.; Denys, A.; Depeursinge, A.; Schaefer, N. Signature of Survival: A ${ }^{18}$ F-FDG PET Based Whole-Liver Radiomic Analysis Predicts Survival after 90Y-TARE for Hepatocellular Carcinoma. Oncotarget 2018, 9, 4549-4558. [CrossRef]

302. Nakajo, M.; Jinguji, M.; Nakajo, M.; Shinaji, T.; Nakabeppu, Y.; Fukukura, Y.; Yoshiura, T. Texture Analysis of FDG PET/CT for Differentiating between FDG-Avid Benign and Metastatic Adrenal Tumors: Efficacy of Combining SUV and Texture Parameters. Abdom. Radiol. 2017, 42, 2882-2889. [CrossRef]

303. Branchini, M.; Zorz, A.; Zucchetta, P.; Bettinelli, A.; De Monte, F.; Cecchin, D.; Paiusco, M. Impact of Acquisition Count Statistics Reduction and SUV Discretization on PET Radiomic Features in Pediatric ${ }^{18}$ F-FDG-PET/MRI Examinations. Phys. Med. 2019, 59, 117-126. [CrossRef] [PubMed]

304. Galavis, P.E.; Hollensen, C.; Jallow, N.; Paliwal, B.; Jeraj, R. Variability of Textural Features in FDG PET Images Due to Different Acquisition Modes and Reconstruction Parameters. Acta Oncol. 2010, 49, 1012-1016. [CrossRef] [PubMed]

305. Yang, P.; Xu, L.; Cao, Z.; Wan, Y.; Xue, Y.; Jiang, Y.; Yen, E.; Luo, C.; Wang, J.; Rong, Y.; et al. Extracting and Selecting Robust Radiomic Features from PET/MR Images in Nasopharyngeal Carcinoma. Mol. Imaging Biol. 2020, 22, 1581-1591. [CrossRef]

306. Oliver, J.A.; Budzevich, M.; Zhang, G.G.; Dilling, T.J.; Latifi, K.; Moros, E.G. Variability of Image Features Computed from Conventional and Respiratory-Gated PET/CT Images of Lung Cancer. Transl. Oncol. 2015, 8, 524-534. [CrossRef]

307. Shiri, I.; Rahmim, A.; Ghaffarian, P.; Geramifar, P.; Abdollahi, H.; Bitarafan-Rajabi, A. The Impact of Image Reconstruction Settings on ${ }^{18}$ F-FDG PET Radiomic Features: Multi-Scanner Phantom and Patient Studies. Eur. Radiol. 2017, 27, 4498-4509. [CrossRef]

308. Bailly, C.; Bodet-Milin, C.; Couespel, S.; Necib, H.; Kraeber-Bodéré, F.; Ansquer, C.; Carlier, T. Revisiting the Robustness of PET-Based Textural Features in the Context of Multi-Centric Trials. PLoS ONE 2016, 11, e0159984. [CrossRef] [PubMed]

309. Yip, S.; McCall, K.; Aristophanous, M.; Chen, A.B.; Aerts, H.J.W.L.; Berbeco, R. Comparison of Texture Features Derived from Static and Respiratory-Gated PET Images in Non-Small Cell Lung Cancer. PLoS ONE 2014, 9, e115510. [CrossRef] [PubMed]

310. Vallières, M.; Laberge, S.; Diamant, A.; El Naqa, I. Enhancement of Multimodality Texture-Based Prediction Models via Optimization of PET and MR Image Acquisition Protocols: A Proof of Concept. Phys. Med. Biol. 2017, 62, 8536-8565. [CrossRef] 
311. Oliver, J.A.; Budzevich, M.; Hunt, D.; Moros, E.G.; Latifi, K.; Dilling, T.J.; Feygelman, V.; Zhang, G. Sensitivity of Image Features to Noise in Conventional and Respiratory-Gated PET/CT Images of Lung Cancer: Uncorrelated Noise Effects. Technol. Cancer Res. Treat. 2017, 16, 595-608. [CrossRef]

312. Noortman, W.A.; Vriens, D.; Slump, C.H.; Bussink, J.; Meijer, T.W.H.; de Geus-Oei, L.-F.; van Velden, F.H.P. Adding the Temporal Domain to PET Radiomic Features. PLoS ONE 2020, 15, e239438. [CrossRef]

313. Leijenaar, R.T.H.; Nalbantov, G.; Carvalho, S.; van Elmpt, W.J.C.; Troost, E.G.C.; Boellaard, R.; Aerts, H.J.W.L.; Gillies, R.J.; Lambin, P. The Effect of SUV Discretization in Quantitative FDG-PET Radiomics: The Need for Standardized Methodology in Tumor Texture Analysis. Sci. Rep. 2015, 5, 11075. [CrossRef] [PubMed]

314. Lu, L.; Lv, W.; Jiang, J.; Ma, J.; Feng, Q.; Rahmim, A.; Chen, W. Robustness of Radiomic Features in [11C]Choline and $\left[{ }^{18}\right.$ F]FDG PET/CT Imaging of Nasopharyngeal Carcinoma: Impact of Segmentation and Discretization. Mol. Imaging Biol. 2016, 18, 935-945. [CrossRef]

315. Guezennec, C.; Bourhis, D.; Orlhac, F.; Robin, P.; Corre, J.-B.; Delcroix, O.; Gobel, Y.; Schick, U.; Salaün, P.-Y.; Abgral, R. InterObserver and Segmentation Method Variability of Textural Analysis in Pre-Therapeutic FDG PET/CT in Head and Neck Cancer. PLoS ONE 2019, 14, e0214299. [CrossRef] [PubMed]

316. Aide, N.; Salomon, T.; Blanc-Fournier, C.; Grellard, J.-M.; Levy, C.; Lasnon, C. Implications of Reconstruction Protocol for Histo-Biological Characterisation of Breast Cancers Using FDG-PET Radiomics. EJNMMI Res. 2018, 8, 114. [CrossRef] [PubMed]

317. Hatt, M.; Tixier, F.; Cheze Le Rest, C.; Pradier, O.; Visvikis, D. Robustness of Intratumor ${ }^{18}$ F-FDG PET Uptake Heterogeneity Quantification for Therapy Response Prediction in Oesophageal Carcinoma. Eur. J. Nucl. Med. Mol. Imaging 2013, 40, 1662-1671. [CrossRef]

318. Belli, M.L.; Mori, M.; Broggi, S.; Cattaneo, G.M.; Bettinardi, V.; Dell'Oca, I.; Fallanca, F.; Passoni, P.; Vanoli, E.G.; Calandrino, R.; et al. Quantifying the Robustness of $\left[{ }^{18}\right.$ F]FDG-PET/CT Radiomic Features with Respect to Tumor Delineation in Head and Neck and Pancreatic Cancer Patients. Phys. Med. 2018, 49, 105-111. [CrossRef]

319. Bashir, U.; Azad, G.; Siddique, M.M.; Dhillon, S.; Patel, N.; Bassett, P.; Landau, D.; Goh, V.; Cook, G. The Effects of Segmentation Algorithms on the Measurement of ${ }^{18}$ F-FDG PET Texture Parameters in Non-Small Cell Lung Cancer. EJNMMI Res. 2017, 7, 60. [CrossRef]

320. Orlhac, F.; Nioche, C.; Soussan, M.; Buvat, I. Understanding Changes in Tumor Texture Indices in PET: A Comparison Between Visual Assessment and Index Values in Simulated and Patient Data. J. Nucl. Med. 2017, 58, 387-392. [CrossRef]

321. Lovat, E.; Siddique, M.; Goh, V.; Ferner, R.E.; Cook, G.J.R.; Warbey, V.S. The Effect of Post-Injection ${ }^{18}$ F-FDG PET Scanning Time on Texture Analysis of Peripheral Nerve Sheath Tumors in Neurofibromatosis-1. EJNMMI Res. 2017, 7, 35. [CrossRef] [PubMed]

322. Cheng, N.-M.; Fang, Y.-H.D.; Tsan, D.-L.; Hsu, C.-H.; Yen, T.-C. Respiration-Averaged CT for Attenuation Correction of PET ImagesImpact on PET Texture Features in Non-Small Cell Lung Cancer Patients. PLoS ONE 2016, 11, e0150509. [CrossRef] [PubMed]

323. Garcia-Vicente, A.M.; Molina, D.; Pérez-Beteta, J.; Amo-Salas, M.; Martínez-González, A.; Bueno, G.; Tello-Galán, M.J.; SorianoCastrejón, Á. Textural Features and SUV-Based Variables Assessed by Dual Time Point ${ }^{18}$ F-FDG PET/CT in Locally Advanced Breast Cancer. Ann. Nucl. Med. 2017, 31, 726-735. [CrossRef] [PubMed]

324. Forgács, A.; Béresová, M.; Garai, I.; Lassen, M.L.; Beyer, T.; DiFranco, M.D.; Berényi, E.; Balkay, L. Impact of Intensity Discretization on Textural Indices of $\left[{ }^{18}\right.$ F]FDG-PET Tumor Heterogeneity in Lung Cancer Patients. Phys. Med. Biol. 2019, 64, 125016. [CrossRef]

325. Grootjans, W.; Tixier, F.; van der Vos, C.S.; Vriens, D.; Le Rest, C.C.; Bussink, J.; Oyen, W.J.G.; de Geus-Oei, L.-F.; Visvikis, D.; Visser, E.P. The Impact of Optimal Respiratory Gating and Image Noise on Evaluation of Intratumor Heterogeneity on ${ }^{18}$ F-FDG PET Imaging of Lung Cancer. J. Nucl. Med. 2016, 57, 1692-1698. [CrossRef] [PubMed]

326. Lasnon, C.; Majdoub, M.; Lavigne, B.; Do, P.; Madelaine, J.; Visvikis, D.; Hatt, M.; Aide, N. ${ }^{18}$ F-FDG PET/CT Heterogeneity Quantification through Textural Features in the Era of Harmonisation Programs: A Focus on Lung Cancer. Eur. J. Nucl. Med. Mol. Imaging 2016, 43, 2324-2335. [CrossRef]

327. Doumou, G.; Siddique, M.; Tsoumpas, C.; Goh, V.; Cook, G.J. The Precision of Textural Analysis in (18)F-FDG-PET Scans of Oesophageal Cancer. Eur. Radiol. 2015, 25, 2805-2812. [CrossRef]

328. Forgacs, A.; Pall Jonsson, H.; Dahlbom, M.; Daver, F.; DiFranco, M.D.; Opposits, G.; Krizsan, A.K.; Garai, I.; Czernin, J.; Varga, J.; et al. A Study on the Basic Criteria for Selecting Heterogeneity Parameters of F18-FDG PET Images. PLoS ONE 2016, 11, e0164113. [CrossRef]

329. Paul, D.; Su, R.; Romain, M.; Sébastien, V.; Pierre, V.; Isabelle, G. Feature Selection for Outcome Prediction in Oesophageal Cancer Using Genetic Algorithm and Random Forest Classifier. Comput. Med. Imaging Graph. 2017, 60, 42-49. [CrossRef]

330. Smeets, E.M.M.; Withaar, D.S.; Grootjans, W.; Hermans, J.J.; van Laarhoven, K.; de Geus-Oei, L.-F.; Gotthardt, M.; Aarntzen, E.H.J.G. Optimal Respiratory-Gated [ ${ }^{18}$ F]FDG PET/CT Significantly Impacts the Quantification of Metabolic Parameters and Their Correlation with Overall Survival in Patients with Pancreatic Ductal Adenocarcinoma. EJNMMI Res. 2019, 9, 24. [CrossRef]

331. Desseroit, M.-C.; Tixier, F.; Weber, W.A.; Siegel, B.A.; Cheze Le Rest, C.; Visvikis, D.; Hatt, M. Reliability of PET/CT Shape and Heterogeneity Features in Functional and Morphologic Components of Non-Small Cell Lung Cancer Tumors: A Repeatability Analysis in a Prospective Multicenter Cohort. J. Nucl. Med. 2017, 58, 406-411. [CrossRef]

332. Altazi, B.A.; Zhang, G.G.; Fernandez, D.C.; Montejo, M.E.; Hunt, D.; Werner, J.; Biagioli, M.C.; Moros, E.G. Reproducibility of F18FDG PET Radiomic Features for Different Cervical Tumor Segmentation Methods, Gray-Level Discretization, and Reconstruction Algorithms. J. Appl. Clin. Med. Phys. 2017, 18, 32-48. [CrossRef] [PubMed] 
333. Brooks, F.J.; Grigsby, P.W. Low-Order Non-Spatial Effects Dominate Second-Order Spatial Effects in the Texture Quantifier Analysis of ${ }^{18}$ F-FDG-PET Images. PLoS ONE 2015, 10, e0116574. [CrossRef] [PubMed]

334. Lv, W.; Yuan, Q.; Wang, Q.; Ma, J.; Jiang, J.; Yang, W.; Feng, Q.; Chen, W.; Rahmim, A.; Lu, L. Robustness versus Disease Differentiation When Varying Parameter Settings in Radiomics Features: Application to Nasopharyngeal PET/CT. Eur. Radiol. 2018, 28, 3245-3254. [CrossRef]

335. Reynés-Llompart, G.; Sabaté-Llobera, A.; Llinares-Tello, E.; Martí-Climent, J.M.; Gámez-Cenzano, C. Image Quality Evaluation in a Modern PET System: Impact of New Reconstructions Methods and a Radiomics Approach. Sci. Rep. 2019, 9, 10640. [CrossRef]

336. Orlhac, F.; Boughdad, S.; Philippe, C.; Stalla-Bourdillon, H.; Nioche, C.; Champion, L.; Soussan, M.; Frouin, F.; Frouin, V.; Buvat, I. A Postreconstruction Harmonization Method for Multicenter Radiomic Studies in PET. J. Nucl. Med. 2018, 59, 1321-1328. [CrossRef] [PubMed]

337. Xie, C.; Du, R.; Ho, J.W.; Pang, H.H.; Chiu, K.W.; Lee, E.Y.; Vardhanabhuti, V. Effect of Machine Learning Re-Sampling Techniques for Imbalanced Datasets in ${ }^{18}$ F-FDG PET-Based Radiomics Model on Prognostication Performance in Cohorts of Head and Neck Cancer Patients. Eur. J. Nucl. Med. Mol. Imaging 2020, 47, 2826-2835. [CrossRef]

338. Yip, S.S.F.; Parmar, C.; Kim, J.; Huynh, E.; Mak, R.H.; Aerts, H.J.W.L. Impact of Experimental Design on PET Radiomics in Predicting Somatic Mutation Status. Eur. J. Radiol. 2017, 97, 8-15. [CrossRef]

339. Boughdad, S.; Nioche, C.; Orlhac, F.; Jehl, L.; Champion, L.; Buvat, I. Influence of Age on Radiomic Features in ${ }^{18}$ F-FDG PET in Normal Breast Tissue and in Breast Cancer Tumors. Oncotarget 2018, 9, 30855-30868. [CrossRef]

340. WHO I World Health Organization. Available online: https://www.who.int/ (accessed on 25 November 2020).

341. Clark, K.; Vendt, B.; Smith, K.; Freymann, J.; Kirby, J.; Koppel, P.; Moore, S.; Phillips, S.; Maffitt, D.; Pringle, M.; et al. The Cancer Imaging Archive (TCIA): Maintaining and Operating a Public Information Repository. J. Digit. Imaging 2013, 26, 1045-1057. [CrossRef]

342. Kaissis, G.A.; Makowski, M.R.; Rückert, D.; Braren, R.F. Secure, Privacy-Preserving and Federated Machine Learning in Medical Imaging. Nat. Mach. Intell. 2020, 2, 305-311. [CrossRef]

343. Sheller, M.J.; Edwards, B.; Reina, G.A.; Martin, J.; Pati, S.; Kotrotsou, A.; Milchenko, M.; Xu, W.; Marcus, D.; Colen, R.R.; et al. Federated Learning in Medicine: Facilitating Multi-Institutional Collaborations without Sharing Patient Data. Sci. Rep. 2020, 10, 12598. [CrossRef] [PubMed]

344. Welch, M.L.; McIntosh, C.; Haibe-Kains, B.; Milosevic, M.F.; Wee, L.; Dekker, A.; Huang, S.H.; Purdie, T.G.; O'Sullivan, B.; Aerts, H.J.W.L.; et al. Vulnerabilities of Radiomic Signature Development: The Need for Safeguards. Radiother. Oncol. 2019, 130, 2-9. [CrossRef] [PubMed]

345. Van Griethuysen, J.J.M.; Fedorov, A.; Parmar, C.; Hosny, A.; Aucoin, N.; Narayan, V.; Beets-Tan, R.G.H.; Fillion-Robin, J.C.; Pieper, S.; Aerts, H.J.W.L. Computational Radiomics System to Decode the Radiographic Phenotype. Cancer Res. 2017, 77, e104-e107. [CrossRef] [PubMed]

346. Van Duijn, P.W.; Marques, R.B.; Ziel-van der Made, A.C.J.; van Zoggel, H.J.A.A.; Aghai, A.; Berrevoets, C.; Debets, R.; Jenster, G.; Trapman, J.; van Weerden, W.M. Tumor Heterogeneity, Aggressiveness, and Immune Cell Composition in a Novel Syngeneic PSA-Targeted Pten Knockout Mouse Prostate Cancer (MuCaP) Model. Prostate 2018, 78, 1013-1023. [CrossRef] [PubMed]

347. Januškevičienè, I.; Petrikaitè, V. Heterogeneity of Breast Cancer: The Importance of Interaction between Different Tumor Cell Populations. Life Sci. 2019, 239, 117009. [CrossRef] [PubMed]

348. Cherezov, D.; Goldgof, D.; Hall, L.; Gillies, R.; Schabath, M.; Müller, H.; Depeursinge, A. Revealing Tumor Habitats from Texture Heterogeneity Analysis for Classification of Lung Cancer Malignancy and Aggressiveness. Sci. Rep. 2019, 9, 4500. [CrossRef] [PubMed]

349. Marusyk, A.; Almendro, V.; Polyak, K. Intra-Tumor Heterogeneity: A Looking Glass for Cancer? Nat. Rev. Cancer 2012, 12, 323-334. [CrossRef] [PubMed]

350. Junttila, M.R.; de Sauvage, F.J. Influence of Tumor Micro-Environment Heterogeneity on Therapeutic Response. Nature 2013, 501, 346-354. [CrossRef]

351. Robinson, M.H.; Vasquez, J.; Kaushal, A.; MacDonald, T.J.; Velázquez Vega, J.E.; Schniederjan, M.; Dhodapkar, K. Subtype and Grade-Dependent Spatial Heterogeneity of T-Cell Infiltration in Pediatric Glioma. J. Immunother. Cancer 2020, 8, e001066. [CrossRef]

352. Traverso, A.; Wee, L.; Dekker, A.; Gillies, R. Repeatability and Reproducibility of Radiomic Features: A Systematic Review. Int. J. Radiat. Oncol. Biol. Phys. 2018, 102, 1143-1158. [CrossRef] [PubMed]

353. Avanzo, M.; Wei, L.; Stancanello, J.; Vallières, M.; Rao, A.; Morin, O.; Mattonen, S.A.; El Naqa, I. Machine and Deep Learning Methods for Radiomics. Med. Phys. 2020, 47. [CrossRef]

354. Mayerhoefer, M.E.; Materka, A.; Langs, G.; Häggström, I.; Szczypiński, P.; Gibbs, P.; Cook, G. Introduction to Radiomics. J. Nucl. Med. 2020, 61, 488-495. [CrossRef] 